\title{
Numerical modeling of turbulent dispersion for wind-driven rain on building facades
}

\author{
A. Kubilay ${ }^{\mathrm{a}, \mathrm{b}, *}$, D. Derome ${ }^{\mathrm{a}, \mathrm{b}}$, B. Blocken ${ }^{\mathrm{c}}$, J. Carmeliet ${ }^{\mathrm{a}, \mathrm{b}}$ \\ ${ }^{a}$ Chair of Building Physics, Swiss Federal Institute of Technology ETHZ, Zurich, Switzerland \\ ${ }^{b}$ EMPA, Swiss Federal Laboratories for Materials Testing and Research, Laboratory for Building Technologies, Dübendorf, \\ Switzerland \\ ${ }^{c}$ Building Physics and Services, Eindhoven University of Technology, Eindhoven, The Netherlands \\ * Corresponding author: Aytac Kubilay, Institute of Technology in Architecture, Chair of Building Physics, ETH Zurich, Wolfgang- \\ Pauli-Strasse 15, CH-8093, Zurich, Switzerland.Tel.: +41 58765 4276; E-mail address: kubilay@arch.ethz.ch
}

\begin{abstract}
Wind-driven rain (WDR) is one of the most important moisture sources with potential negative effects on the hygrothermal performance and durability of building facades. The impact of WDR on building facades can be understood in a better way by predicting the surface wetting distribution accurately. Computational Fluid Dynamics (CFD) simulations can be used to obtain accurate spatial and temporal information on WDR. In many previous numerical WDR studies, the turbulent dispersion of the raindrops has been neglected. However, it is not clear to what extent this assumption is justified, and to what extent the deviations between the experimental and the numerical results in previous studies can be attributed to the absence of turbulent dispersion in the model. In this paper, an implementation of turbulent dispersion into an Eulerian Multiphase (EM) model for WDR assessment is proposed. First, CFD WDR simulations are performed for a simplified isolated high-rise building, with and without turbulent dispersion. It is shown that the turbulence intensity field in the vicinity of the building, and correspondingly the turbulence kinetic energy field, has a strong influence on the estimated catch ratio values when turbulent dispersion is taken into account. Next, CFD WDR simulations are made for a monumental tower building, for which experimental data are available. It is shown that taking turbulent dispersion into account reduces the average deviation between simulations and measurements from $24 \%$ to $15 \%$.
\end{abstract}

Keywords: Wind-driven rain, Buildings, Computational fluid dynamics (CFD), Eulerian multiphase model, Turbulent dispersion

\section{Introduction}

Wind-driven rain (WDR) is rain with a horizontal velocity component due to its co-occurrence with wind flow. WDR is one of the most important moisture sources that influence the hygrothermal performance and the durability of building facades. It can lead to several harmful phenomena in terms of building physics, such as surface soiling due to runoff, weathering, algae formation, salt damage and frost damage at exterior wall surfaces, and can be a source of moisture leading to mold growth at inside wall surfaces [1, 2]. A recent study also investigated the effect of different rain conditions on a range of building materials and showed the link between surface erosion processes and WDR [3]. Moreover, several authors have indicated structural and performance problems in photovoltaic modules related to moisture ingress and degradation [4-6]. With the forecasted climate change, more severe WDR exposure and increased maintenance requirements of buildings are expected [7]. WDR intensities are used as an important boundary condition in building envelope heat-air-moisture (BE-HAM) transport models, reinforcing the need for accurate information on the spatial and temporal distribution of WDR. The impinging WDR intensity is governed by several parameters, such as building geometry, environment topography, position on the building facade, wind speed, wind direction, rainfall intensity and raindrop-size distribution [8].

Three methods exist for estimating the WDR intensity on building surfaces: (1) measurements, (2) semi-empirical methods and (3) numerical simulations with Computational Fluid Dynamics (CFD). Blocken and Carmeliet [1,2] and Blocken et al. [9] provided extensive reviews of WDR research in building physics. Generally, measurements of WDR on building facades are difficult, timeconsuming and prone to errors [10-12]. They are also confined to the meteorological conditions present at the time of experiments. Semi-empirical methods on the other hand are fast and easy to use but they only give approximations and they cannot provide detailed information. For example, in the ISO Standard for WDR [13, 14], the mutual influence of buildings on WDR intensity is taken into account by a simplified reduction factor, called the obstruction factor. Blocken et al. [15] showed that there may be cases where particular parts of the building are actually exposed to a higher amount of WDR due to the influence of another building, contrary to what the obstruction factor would estimate. Therefore, semi-empirical methods are generally suitable only for stand-alone buildings in simple configurations, or for preliminary analysis. These methods will not give accurate results in cases of complex flows around buildings due to the influence of the surrounding buildings. Furthermore, both measurements and semi-empirical methods are limited in terms of spatial resolution. As a result, in BE-HAM models, the WDR intensity is often considered uniform across large parts of the facade. This in turn may lead to large errors in BE-HAM simulations for building facades, as in reality, the WDR intensity far from uniform across the facade. 
CFD simulations can be a valuable alternative to measurements and semi-empirical methods. Although CFD simulations are often complex and time consuming, they can be used to obtain accurate spatial and temporal information on WDR. Furthermore, once the numerical simulation method is validated, it can be used for other (real or theoretical) rain events, at least for similar geometries, in much shorter times compared to experimental (full-scale or wind tunnel) methods. Blocken et al. [16] and Moonen et al. [17] provide overviews of applications of CFD in urban physics and building performance simulation. Blocken et al. [18] compared two different semi-empirical models with CFD simulations for two case studies, for which full-scale measurements were available. The agreement between measurements and CFD was found to be quite good with an average discrepancy of 20-25\%. On the other hand, the results predicted by semi-empirical models provided discrepancies up to a factor of 2 to 5 . The vast majority of CFD simulations of WDR in the past was based on the steady-state numerical solution technique developed by Choi [19-22], which is based on the combined application of the 3D steady Reynolds-Averaged Navier-Stokes (RANS) equations (often with a $k-\varepsilon$ model) and Lagrangian Particle Tracking (LPT). Blocken and Carmeliet [8] extended Choi's simulation technique by adding the temporal component, allowing the determination of both the spatial and temporal distribution of WDR for transient rain events. However, previous studies on WDR have mostly neglected turbulent dispersion. The neglect of turbulent dispersion is a valid assumption only for the non-oblique flows on the windward facade of an isolated building with a small wind-blocking effect $[2,8,23]$. The wind-blocking effect is the disturbance of the wind-flow pattern by the presence of the building. That is why the validation studies on WDR have mostly focused on the rain events with wind directions perpendicular to the windward facade of simple isolated buildings [8, 24-27]. Even though the selection of such rain events decreases the influence of turbulent dispersion, the discrepancies are largely attributed to the neglect of turbulent dispersion, especially at lower parts of the buildings. The influence of turbulent dispersion on the WDR intensities on building facades is considered to increase for multi-building configurations due to the resulting recirculation regions with low wind speed between the buildings.

It has been shown that Eulerian Multiphase (EM) model with RANS can give accurate results for WDR on the windward facade of an isolated low-rise building [28]. Kubilay et al. [29] performed a validation study with the EM model on a historical building with a monumental tower by comparing the results with measurement data and numerical data from the LPT model. It has been shown that the user time spent for the simulation of a single building decreases by at least a factor of 10 using the EM model compared to the LPT model. Furthermore, the EM model allows the calculation of catch ratios on all surfaces of a complex geometry with several buildings in a single calculation. However, in urban environments, the wind flow will be influenced by other buildings or objects in the vicinity, leading to recirculation regions between buildings where the wind speed values are low. In such cases, the raindrop trajectories can be almost parallel to the facade. Turbulent dispersion in the streamwise direction can cause these raindrops to deviate from their mean trajectory and to hit the facade. Therefore, as the geometry and the air flow get more complex, neglecting turbulent dispersion might lead to erroneous results.

To the knowledge of the authors, there are not many studies that tried to quantify the effects of turbulent dispersion on WDR intensities. Lakehal et al. [30] used a Markov chain to model the velocity fluctuations and found that turbulent dispersion is an important factor increasing WDR on vertical walls in cases with weak upstream wind flow, such as in street canyon. This work showed that the effect of turbulent dispersion can be large, in some cases as important as the mean flow. Choi [23] modeled the effect of gusts on WDR intensities on the windward facade of a cubic building using LPT model. The work followed a stochastic approach to model the fluctuations and superimposed them on the mean wind velocity. This approach required a large number of runs as the fluctuations were random. Hangan [31] used a random walk model for turbulent dispersion of droplets on two geometries and compared the results with wind tunnel measurements. The WDR distribution showed large discrepancies compared to experimental data. Furthermore, the study did not report the WDR intensities without turbulent dispersion modeling. Etyemezian [32] discussed that the effect of turbulence is not negligible for trajectories of individual drops but small when large surface areas of the building are considered. However, the study only focused on three raindrop sizes (1.25 mm, $2.5 \mathrm{~mm}$ and $5 \mathrm{~mm})$. van Mook [27] applied a similar model for a high-rise building and found that, with turbulent dispersion, smaller raindrops are more easily driven onto the facade, leading to higher catch ratio values than in the case without turbulent dispersion. However, this study showed large differences of WDR across the facade, possibly due to random processes involved in the model and smaller number of runs than required.

The EM model can provide a more direct approach to include turbulent dispersion in WDR calculations. Recently, Huang and Li [33] presented transient WDR calculations using large eddy simulation (LES). As valuable as their work is in terms of the simulation of the transient aspects of WDR, simulation of a long real-life transient rain event with LES would be too computationally expensive. Therefore, in the present paper, a steady-state modeling approach is proposed to include turbulent dispersion in WDR calculations. CFD simulations of WDR using 3D steady RANS with the EM model are performed for two different building geometries. Section 2 presents the governing equations and the modeling approach for turbulent dispersion used in this study. Section 3 explains how the WDR parameters are obtained from the simulation results. The computational setup, the boundary conditions and the settings for the numerical simulations are given in section 4. In section 5, CFD simulation results of WDR are compared with and without turbulent dispersion modeling for a simplified isolated high-rise building. In section 6, CFD simulation results of WDR with and without 
turbulent dispersion model are compared for a monumental tower building with available measurement data. Finally, sections 7 and 8 provide a general discussion and conclusion, respectively.

\section{Methodology}

In the EM model, the rain phase is regarded as a continuum, as is the air phase. Each class of raindrop size is treated as a different phase, as each group of raindrops with similar size will interact with the wind flow field in a similar way. Using the EM model, a boundary condition is imposed for each rain phase at the inlet boundaries. Then, the governing equations are solved and the WDR intensities are calculated by an integration over all classes of raindrop sizes on all building facades in a single calculation. The governing equations of the EM model are detailed in the next section.

\subsection{Governing equations for the air phase}

In the present study, 3D steady RANS with the realizable $k-\varepsilon$ model [34] is used for the incompressible wind flow simulations:

$\frac{\partial \bar{u}_{i}}{\partial x_{i}}=0$

$\frac{\partial\left(\bar{u}_{i} \bar{u}_{j}\right)}{\partial x_{j}}=-\frac{1}{\rho_{a}} \frac{\partial \bar{p}}{\partial x_{i}}+\frac{\partial}{\partial x_{j}}\left(v_{a}\left[\frac{\partial \bar{u}_{i}}{\partial x_{j}}+\frac{\partial \bar{u}_{j}}{\partial x_{i}}\right]-\overline{u_{i}^{\prime} u_{j}^{\prime}}\right)$

$\frac{\partial\left(k \bar{u}_{j}\right)}{\partial x_{j}}=\frac{\partial}{\partial x_{j}}\left[\left(v_{a}+\frac{v_{t, a}}{\sigma_{k}}\right) \frac{\partial k}{\partial x_{j}}\right]+P_{k}-\varepsilon$

$\frac{\partial\left(\varepsilon \bar{u}_{j}\right)}{\partial x_{j}}=\frac{\partial}{\partial x_{j}}\left[\left(v_{a}+\frac{v_{t, a}}{\sigma_{\varepsilon}}\right) \frac{\partial \varepsilon}{\partial x_{j}}\right]+C_{1} S \varepsilon-C_{2} \frac{\varepsilon^{2}}{k+\sqrt{v_{a} \varepsilon}}$

$v_{t, a}=C_{\mu} \frac{k^{2}}{\varepsilon}$

where $u_{i}$ denotes the velocity component of wind in direction $\mathrm{i}$ (where $\mathrm{i}=1$ is $\mathrm{x}$-direction, $\mathrm{i}=2$ is $\mathrm{y}$-direction, $\mathrm{i}=3$ is $\mathrm{z}$-direction), $\rho_{a}$ the density of air, $p$ the pressure, $k$ the turbulence kinetic energy, $\varepsilon$ the turbulence dissipation rate, $v_{t, a}$ the kinematic turbulent viscosity of air, $v_{a}$ the kinematic viscosity of air, $\sigma_{k}$ the turbulent Prandtl number for $k, \sigma_{\varepsilon}$ the turbulent Prandtl number for $\varepsilon, P_{k}$ the generation of turbulence kinetic energy due to mean velocity gradients, $S$ the modulus of the mean rate of strain tensor. $C_{2}$ is a model constant. $C_{\mu}$ is a function that depends on the mean strain and rotation rates, the angular velocity of the system rotation and the turbulence fields $\left(k\right.$ and $\varepsilon$ ). The overbar denotes Reynolds averaging. The following model constants are used in the present study: $C_{2}=1.92, \sigma_{k}=1.0$, $\sigma_{\varepsilon}=1.2$. Furthermore, $C_{1}=\max \{0.43, \eta /(5+\eta)\}$, where $\eta$ is a function of the time scale ratio of the turbulence to the mean strain. In the realizable $k-\varepsilon$ model, the Reynolds stresses are modeled using the turbulent viscosity, $v_{t, a}$, which is assumed to be an isotropic quantity.

\subsection{Governing equations for the rain phases}

In order to derive, for each phase, equations valid throughout the flow domain, individual phases are distinguished by conditioning, which is provided by multiplying each conservation equation by a phase indicator function, $X_{k}$, defined as follows [35]:

$\chi_{k}(x, t)= \begin{cases}1 & \text { phase } k \text { present at }(x, t) \\ 0 & \text { otherwise }\end{cases}$

The conditional-averaged phase quantities, or the average quantities relating to one particular phase only, are defined after Reynolds averaging as:

$\bar{\phi}=\frac{\overline{\chi_{k} \phi}}{\alpha_{k}}$

where $\alpha_{k}$ is the phase fraction of rain phase $k$, which represents a specific class of raindrop size, and $\phi$ is the quantity under consideration. By using conditional-averaging, the continuity equation for the incompressible rain phase becomes [28, 29, 36]: 
$\frac{\partial \alpha_{k}}{\partial t}+\frac{\partial\left(\alpha_{k} \bar{u}_{k, j}\right)}{\partial x_{j}}=0$

(no summation over $k$ )

where $u_{k, j}$ denotes the velocity component of $k^{\text {th }}$ phase of rain. Similarly, the momentum equation becomes:

$\frac{\partial \alpha_{k} \bar{u}_{k, i}}{\partial t}+\frac{\partial\left(\alpha_{k} \bar{u}_{k, i} \bar{u}_{k, j}\right)}{\partial x_{j}}+\frac{\partial\left(\alpha_{k} \overline{u_{k, i}^{\prime} u_{k, j}^{\prime}}\right)}{\partial x_{j}}=\alpha_{k} g+\alpha_{k} \frac{3 \mu_{a}}{\rho_{w} d^{2}} \frac{C_{d} \operatorname{Re}_{R}}{4}\left(\bar{u}_{i}-\bar{u}_{k, i}\right) \quad$ (no summation over $k$ )

where $d$ is the raindrop diameter, $u_{i}$ the velocity component of wind in direction $i, \rho_{w}$ the density of the raindrops, $\mu_{a}$ is the dynamic air viscosity, $g$ the gravitational acceleration, $C_{d}$ the drag coefficient. $\operatorname{Re}_{R}$ denotes the relative Reynolds number and is calculated as follows:

$\operatorname{Re}_{R}=\frac{\rho_{a} d}{\mu_{a}}\left\|\vec{u}-\overrightarrow{u_{k}}\right\|$

where $\vec{u}$ is the air phase velocity vector and $\overrightarrow{u_{k}}$ is the rain phase velocity vector. Rain phase calculations are one-way coupled with the air phase, which means that the air phase influences the rain phase, but not the other way around. This is a valid assumption as the volumetric ratio of rain in air is below $1 \times 10^{-3}$ for rainfall intensities up to $20 \mathrm{~mm} / \mathrm{h}$ and below $1 \times 10^{-2}$ for even the most severe cases according to the distribution by de Wolf [37] that provides the distribution density of raindrop diameters.

The third term on the left-hand side in Eq. (9) corresponds to the turbulent mass flux, which was neglected in many earlier WDR modeling efforts. In the present study, the molecular mass flux is assumed negligible in comparison to the convective and turbulent mass fluxes [38, 39]. Furthermore, it is assumed that there is no mass transfer between phases. Generally, the inter-phase momentum transfer between phases is composed of components due to drag, lift, virtual mass and other forces like the Basset force. Drag and gravity are the predominant forces expected in most two-phase flow systems [40], and other forces than those two are neglected.

\subsection{Rain phase turbulence closure}

Reynolds stresses are modeled according to the Boussinesq eddy viscosity approximation [41]:

$-\overline{u_{k, i}^{\prime} u_{k, j}^{\prime}}=v_{t, d}\left(\frac{\partial \overline{u_{k, i}^{\prime}}}{\partial x_{j}}+\frac{\partial \overline{u_{k, j}^{\prime}}}{\partial x_{i}}-\frac{2}{3} \frac{\partial \overline{u_{k, k}^{\prime}}}{\partial x_{k}} \delta_{i j}\right)-\frac{2}{3} k_{d} \delta_{i j}$

where $v_{t, d}$ is the turbulent kinematic viscosity of the rain phase, $k_{d}$ is the turbulence kinetic energy of the rain phase and $\delta_{i j}$ is the Kronecker delta. Here, the Reynolds stresses are related to the mean shear rate by the turbulent viscosity, which is calculated as shown in Eq. (5) for the air phase. In the present study, as the transport equations for $k$ and $\varepsilon$ are not solved for the rain phases, the fluctuations of the rain phase velocity should be modeled in a different way.

Issa and Oliveira [42] Shirolkar et al. [43], Hill [35] and Rusche [36] provided a list of various approaches to relate the eddy viscosities of both phases to each other, including both solid-liquid and gas-liquid flows. Politis [44] originally defined the response coefficient, $C_{t}$, which relates the dispersed phase velocity fluctuations to the continuous phase velocity fluctuations. Hill [35] argued that the definition of $C_{t}$ by Politis [44] includes many implied assumptions and generalized its definition by using the relation:

$C_{t}=\frac{u_{d, R M S}^{\prime}}{u_{a, R M S}^{\prime}}$

where $u_{d, R M S}^{\prime}$ and $u_{a, R M S}^{\prime}$ are the root mean square of the velocity fluctuations of the rain phase and the air phase, respectively. The response of the raindrops to the wind phase fluctuations is assumed to be isotropic, hence the scalar response coefficient, $C_{t}$. Using the definitions in Eq. (11) and Eq. (12), the response coefficient, $C_{t}$, can be related to the turbulence kinetic energy and the turbulent viscosity of the rain phases as shown in Eq. (13) and (14), respectively [36, 42].

$$
\begin{aligned}
& k_{d}=C_{t}^{2} k_{a} \\
& v_{t, d}=C_{t}^{2} v_{t, a}
\end{aligned}
$$


Although the concept of $C_{t}$ is easy to grasp, $C_{t}$ values need to be modeled. Chen and Wood [45] modeled the relation between the continuous and the disperse phase turbulent viscosities for dilute gas-solid flows. However, their work assumed that the mean velocities of the continuous and dispersed phases are the same, neglecting the effect of drag.

Politis [44] modeled the response coefficient, which is applicable to solid-liquid flows, by working with a linearized form of the Lagrangian equation of motion for a particle. The response coefficient is modeled by a relationship between two time scales, namely the mean eddy lifetime and the particle response time, similar to the work of Chen and Wood [45]. As a result, the model gives $C_{t}$ values between 0 and 1 , where $C_{t} \rightarrow 1$ indicates that the particle will follow the continuous phase velocity fluctuations exactly.

By using a similar model, Issa [46] proposed a relation applicable to bubbly flows, where the liquid phase is considered as the continuous phase and the gaseous phase is considered as the dispersed phase. Issa's model gives $C_{t}$ values between 1 and 3 , in conditions where $\rho_{d} / \rho_{c}<1$, where $\rho_{d}$ and $\rho_{c}$ denote the dispersed phase and the continuous phase densities, respectively. However, when the density ratio is chosen as $\rho_{d} / \rho_{c}>1$, as in the case of air and rain, $C_{t}$ values get smaller than 1 , in agreement with the Politismodel.

Melville and Bray [47] related the turbulent viscosity of the dispersed phase and the continuous phase in a solid-liquid flow. The turbulent viscosity values are related to each other using Eq. (15) where $t_{p}$ denotes the particle relaxation time and $t_{f l}$ denotes the Lagrangian fluid time scale. The particle relaxation time is defined as the rate of response of particle acceleration to the relative velocity between the particle and the carrier fluid and is shown in Eq. (16). The Lagrangian fluid time scale can be viewed as the characteristic large eddy lifetime and is defined in Eq. (17) [43].

$$
\begin{aligned}
& \frac{v_{t, d}}{v_{t, a}}=\frac{1}{1+\frac{t_{p}}{t_{f l}}} \\
& t_{p}=\frac{4 \rho_{w} d^{2}}{3 \mu C_{d} \operatorname{Re}_{R}} \\
& t_{f l} \cong 0.2 \frac{k}{\varepsilon}
\end{aligned}
$$

In the present paper, the relations in Eq. (13-17) are used since, in the model by Melville and Bray [47], the volume fraction of the dispersed phase is much smaller than one, as is the case for rain. According to the model applied, in the limit of very small raindrops $\left(t_{p} t_{f l} \rightarrow 0\right)$, the droplets will totally follow the fluid motion and the turbulent viscosity of the rain phase becomes $v_{t, d} \rightarrow v_{t, a}$. On the other hand, larger raindrops are only weakly influenced by the fluctuations in the wind flow.

\section{WDR parameters}

The WDR intensity is usually normalized by the unobstructed horizontal rainfall intensity to yield the specific catch ratio, $\eta_{d}(k)$, and the catch ratio, $\eta$. The specific catch ratio is related to the rain phase, $k$, which is associated with a class of raindrop diameters, $d$. The catch ratio is related to the entire spectrum of raindrop diameters. The quantities of the WDR parameters can be obtained after the calculation of the rain phase volumetric ratio and velocity fields by the following equations:

$$
\begin{aligned}
& \eta_{d}(k)=\frac{R_{w d r}(k)}{R_{h}(k)}=\frac{\alpha_{k}\left|V_{n}(k)\right|}{R_{h} f_{h}(k)} \\
& \eta=\int_{d} f_{h}\left(R_{h}, d\right) \eta_{d} \mathrm{~d} d
\end{aligned}
$$

where $R_{w d r}$ denotes the WDR intensity, $R_{h}$ the horizontal rain intensity (i.e. through the horizontal plane), $f_{h}\left(R_{h}, d\right)$ the raindrop size distribution through the horizontal plane [1] and $\left|V_{n}(k)\right|$ the velocity magnitude of rain phase $k$ in the direction normal to the building facade.

In the present study, the raindrop size distribution through the horizontal plane (see Fig. 1) is based on the work of Best [48], which was based on a wide bibliographical survey and measurements for a large number of rain events at various locations. 


\section{Computational settings and parameters}

\subsection{Model geometry and computational domain}

Earlier studies have discussed that the turbulent dispersion can be neglected for low-rise buildings [8, 15, 25]. However, buildings with large wind-blocking effect will lead to a significant decrease in the upstream wind speed values close to the building facade. Blocken et al. [15] stated that the effect of turbulent dispersion could be important for the lower part of high-rise buildings, where the mean rain phase streamlines will be mostly parallel to the windward facade. In that case, even very small deviations from the mean wind speed may lead the raindrops to hit the facade. In this section, the turbulent dispersion model is applied to a simplified isolated high-rise building with dimensions $50 \times 12.5 \times 50 \mathrm{~m}^{3}$ as in the study by Blocken et al. [15]. The computational domain satisfies the guidelines by Tominaga et al. [49] and Franke et al. [50]. The building is located 5H away from the inlet, top and side boundaries, and $15 \mathrm{H}$ away from the outlet boundary, where $\mathrm{H}=50 \mathrm{~m}$ is the height of the building. The blockage ratio of the domain is about $1.5 \%$.

For the grid sensitivity analysis, three structured and purely hexahedral grids are created. The base grid consists of 592,832 cells (see Fig. 2). The coarser grid has 245,632 cells, whereas the finer grid has 1,551,336 cells. The first cell height on the ground and building surfaces has been kept constant for each grid in order to keep the dimensionless wall distance $y+$ the same. The sensitivity analysis has been conducted by comparing mean wind speed along two vertical lines from a height of $0.5 \mathrm{H}$ to $1.5 \mathrm{H}$. The lines are positioned at $0.1 \mathrm{H}$ upstream and with an offset of $0 \mathrm{H}$ and $0.5 \mathrm{H}$ from the symmetry plane, as shown in Fig. 3. The maximum difference between calculated mean wind speed values between the coarser grid and the base grid is $7.9 \%$, the average difference is $1.1 \%$. The maximum difference between the finer grid and the base grid is $5.1 \%$, the average difference is $0.7 \%$. The base grid is chosen for the rest of the study as a trade-off between grid-induced error and computational cost. The cell height on the ground and the building surfaces is $0.01 \mathrm{H}$.

\subsection{Boundary conditions}

\subsubsection{Air phase}

The inlet profile of mean wind speed is defined with the typical log-law expression:

$U(y)=\frac{u^{*}{ }_{A B L}}{\kappa} \ln \left(\frac{y+y_{0}}{y_{0}}\right)$

where $U(y)$ denotes the mean streamwise wind speed at height y above the ground plane, $u_{A B L}{ }_{\text {the }}$ ABL friction velocity, $\kappa$ the von Karman constant ( 0.42 in the present study) and $y_{0}$ the aerodynamic roughness length. In the present study, an aerodynamic roughness length of $0.03 \mathrm{~m}$ is chosen, representing a grass-covered terrain without other obstacles [51]. The ABL friction velocity, $u_{A B L}$, is chosen such that the desired reference wind speed, $U_{10}$, is obtained at $y=10 \mathrm{~m}$.

The inlet profiles of the turbulent quantities $k$ and $\varepsilon$ are defined by Eq. (21) and (22).

$$
\begin{aligned}
& k(y)=\frac{u^{*}{ }_{A B L}^{2}}{\sqrt{C_{\mu}}} \\
& \varepsilon(y)=\frac{u^{*}{ }_{A B L}^{3}}{\kappa\left(y+y_{0}\right)}
\end{aligned}
$$

For wall treatment, the standard wall functions by Launder and Spalding [52], with roughness modification [53], are used. The equivalent sand-grain roughness height $\left(k_{s}\right)$ and the roughness constant $\left(C_{s}\right)$ is determined by the following relation by Blocken et al. [54]:

$k_{s}=\frac{E y_{0}}{C_{S}}$

where $E$ is an empirical constant with a value of 9.793. As long as the given $k_{s}$ value is in the fully-rough regime, only the product $k_{s} C_{s}$ is important and the individual values of the parameters $k_{s}$ and $C_{s}$ have no importance. In OpenFOAM 2.0 [55], the wall function is implemented by the calculation of turbulent viscosity, $v_{t}$, as shown in Eq. (24). 
$v_{t}=v\left(\frac{y^{+} \kappa}{\ln \left(\frac{E y^{+}}{1+C_{s} k_{s}^{+}}\right)}-1\right)$

Note that OpenFOAM ${ }^{\circledR} 2.0$ limits the relation inside the logarithm to be larger than 1 . Any $k_{s} C_{s}$ product that would result in a value below this limit would be truncated, leading to the same wall turbulent viscosity and, thus, the same surface roughness. Such condition exerts a lower limit for the wall-adjacent cell point distance from the ground boundary, which is equal to $k_{s}$. In the present study, for the ground surface, $k_{s}$ is taken to be $0.03 \mathrm{~m}$ and $C_{s}$ is set as 9.7 . The building surfaces are assumed to be smooth.

For the top boundary, constant values are set for $U, k$ and $\varepsilon$ by using the values from the inlet profiles at the same height as suggested by Blocken et al. [54]. This is done in order to limit the horizontal inhomogeneity, as other top boundary conditions, such as symmetry condition, can cause streamwise gradients. Although imposing constant values does not allow fluid to enter or exit the domain, the top boundary is far enough from the building not to cause a problem. A constant static pressure of $0 \mathrm{~Pa}$ is used at the outlet boundary. Symmetry conditions are applied on both sides of the domain.

\subsubsection{Rain phase}

With the definitions established in section 3 , the volumetric ratio of rain phase $k$ can be calculated as:

$\alpha_{k}=\frac{R_{h} f_{h}\left(R_{h}, d\right)}{V_{t}(d)}$

where $V_{t}(d)$ represents the terminal velocity of a raindrop with diameter $d$. The raindrop size distribution through a horizontal plane is shown in Fig. 1. The terminal velocity measurements were made by Gunn and Kinzer [56] and shown in Fig. 4. The implemented drag coefficients should be in agreement with the terminal velocity data, otherwise some artificial acceleration towards the ground can be experienced during simulations even in regions with undisturbed flow field with zero vertical component. In order to overcome this issue, drag coefficients from the same study by Gunn and Kinzer [56] were used.

The value of volumetric ratio of each rain phase, $\alpha_{k}$, is imposed at the inlet and top boundaries. For the rain phase velocity, $u_{k}$, it is assumed that the boundaries are undisturbed and far away from the building in the domain. The vertical inlet rain phase velocity component is set equal to the terminal velocity for that phase. The horizontal inlet rain phase velocity components are set equal to the air phase velocity components, so that the relative velocity between wind and rain is zero at the boundary.

The boundary conditions for the rain phases at the building walls, on the ground and at the outlet are set in such way that the normal gradient of the volumetric ratio, $\partial \alpha_{k} / \partial n$, equals zero when the normal wind velocity vector is pointing out of the domain, and the values of the volumetric ratio, $\alpha_{k}$, are equal to zero when the normal wind velocity vector is pointing into the domain. With these boundary conditions, the interaction between the raindrops and the walls are not modeled and the raindrops leave the domain as soon as they hit a wall boundary, avoiding any inflow of rain phase into the domain due to possible recirculation regions.

\subsection{Solver settings}

OpenFOAM ${ }^{\circledR} 2.0$ is used in this study as the CFD code. It is an open-source, implicit, segregated and double precision solver. An additional solver has been implemented into the code by the authors for solving the governing equations of the rain phases. This additional solver gives the rain phase velocity, volumetric ratio and specific catch ratio distributions.

The pressure-velocity coupling for the wind flow field solution is taken care of with the Semi-Implicit Method for Pressure Linked Equations (SIMPLE) algorithm. Second order discretization schemes are used for both the convection terms and the viscous terms of the governing equations. For the air phase calculations, the simulations are terminated when all the scaled residuals reach $10^{-6}$. For the rain phase calculations, variable values at various locations have been monitored and the calculation is stopped when the values cease convergence.

\subsection{Solution strategy}

The catch ratio is influenced by seven basic parameters: (1) the building and environment geometry, (2) the position on the building facade, (3) the reference wind speed, (4) the reference wind direction, (5) the horizontal rainfall intensity, (6) the horizontal raindrop- 
size distribution and (7) turbulent dispersion [24]. The reference wind direction is chosen to be constant and perpendicular to the wide $\left(50 \times 50 \mathrm{~m}^{2}\right)$ building facade for simplicity.

In the present study, the following steps have been followed:

a. The wind flow field around the building is solved for $U_{10}=10 \mathrm{~m} / \mathrm{s}$. The wind flow field for other values of reference wind speed $\left(U_{10}=1,2,3,5 \mathrm{~m} / \mathrm{s}\right)$ are obtained by linear scaling. Such scaling is allowed for flows around sharp-edged bluff bodies, where the positions of flow separation are independent of the Reynolds number.

b. The turbulent viscosity, $v_{t}$, is scaled linearly for the reference wind speed values, $U_{10}=1,2,3,5 \mathrm{~m} / \mathrm{s}$. Similarly, the turbulence kinetic energy, $k$, is scaled quadratically and the turbulence dissipation rate, $\varepsilon$, is scaled cubicly. In fact, for fully turbulent flow, the turbulence statistics have only a weak dependence on Reynolds number [57]. Wind tunnel measurements by Defraeye [58] for flows around bluff bodies show limited Reynolds number dependency at $\operatorname{Re}>10^{4}$, calculated with reference wind speed and building height.

c. Using each reference wind flow field, specific catch ratio distributions are calculated for several raindrop diameter values (diameters ranging from 0.3 to $1 \mathrm{~mm}$ in steps of $0.1 \mathrm{~mm}$, from 1 to $2 \mathrm{~mm}$ in steps of $0.2 \mathrm{~mm}$ and from 2 to $6 \mathrm{~mm}$ in steps of $1 \mathrm{~mm}$ ). d. Catch ratio distributions are obtained for horizontal rainfall intensities of $R_{h}=0,0.1,0.5,1,2,3,4,5,6,8,10,12,15,20,25$ and 30 $\mathrm{mm} / \mathrm{h}$ using the droplet size distribution as input (see Fig. 1) for each reference wind speed.

\section{Results}

The contour plots for the response coefficient values, $C_{t}$, for raindrop sizes $0.3,1.0,2.0$ and $5.0 \mathrm{~mm}$ in the vertical centerplane of the building for a reference wind speed of $10 \mathrm{~m} / \mathrm{s}$ are shown in Fig. 5 . The $C_{t}$ field in the vicinity of the building is important as it models the relation between the fluctuations of air and rain phases. Note that $C_{t}$ values are equal to one at a sufficient distance from the building for each raindrop size. For the smallest raindrop size of $0.3 \mathrm{~mm}$, in Fig. 5(a), the response coefficient values are larger than 0.9 , except at the rooftop of the building where the flow is separated. For larger raindrop sizes, low $C_{t}$ values are observed in larger areas. $C_{t}$ values get lower at the rooftop of the building as the raindrop size increases. Additionally, the region with low $C_{t}$ values gets larger towards the downstream of the building. Also note that for raindrop size of $2.0 \mathrm{~mm}$, there is a region with $C_{t}$ values lower than 0.8 in front of the building and this region gets larger for raindrop size of $5.0 \mathrm{~mm}$ (see Fig. 5(c-d)). The influence of the wind velocity fluctuations on the rain phase fluctuations gets lower compared to the inertia of raindrops as raindrop size increases. On the contrary, the fluctuations in the raindrop velocity follow the fluctuations in the wind velocity in regions where $C_{t}$ is unity.

Fig. 6 compares the streamlines of raindrop sizes of $0.3,1.0,2.0$ and $3.0 \mathrm{~mm}$ for a wind speed of $10 \mathrm{~m} / \mathrm{s}$ in the vertical centerplane of the building without and with turbulent dispersion. Note that without turbulent dispersion modeling, for the lower two-thirds of the building height, the raindrops travel almost parallel to the building facade. This is especially clear in Fig. 6(a) and (b) for the smallest raindrop size of $0.3 \mathrm{~mm}$, which leads to almost no $\mathrm{x}$-direction velocity component, resulting in small $(<0.05)$ specific catch ratio values (see Eq. (18)). On the other hand, when turbulent dispersion is taken into account, the streamlines are less parallel to the building facade. As a result, the raindrops actually impinge on the facade in contrast to what is predicted without turbulent dispersion. As the raindrops get larger, the influence of turbulent dispersion gets smaller at the upper parts of the building. On the other hand, at the lower parts, the raindrops still impinge on the building with larger angles with the facade, increasing the catch ratio.

\subsection{Specific catch ratio analysis}

The specific catch ratio profiles along two vertical lines on the windward facade of the building, one in the middle of the facade, the other at the side edge, are plotted in Fig. 7 for diameter sizes $d=0.3$ and $1.0 \mathrm{~mm}$ at reference wind speed values of $U_{10}=5$ and 10 $\mathrm{m} / \mathrm{s}$. The solid lines show the specific catch ratio profiles without turbulent dispersion modeling, $\eta_{d}$, the dots the profiles with turbulent dispersion modeling, $\eta^{\prime}{ }_{d}$, and the dotted lines show the quotient of specific catch ratios, $\eta^{\prime}{ }_{d} / \eta_{d}$. The quotient profiles clearly highlight the effect of turbulent dispersion. The increase in absolute values is higher for reference wind speed of $10 \mathrm{~m} / \mathrm{s}$ (Fig. 7(a) and (b)) than for $5 \mathrm{~m} / \mathrm{s}$ (Fig. 7(c) and (d)) for both lines. At higher wind speed values, the fluctuations in the wind velocity increases the velocity of droplets more in the normal direction to the facade. The relative changes shown by quotients, on the other hand, differ for each parameter, i.e. the raindrop size, the reference wind speed, the position of the line on the facade.

The increase, due to taking into account turbulent dispersion, in the specific catch ratio for $d=1.0 \mathrm{~mm}$ is higher than the increase for $d=0.3 \mathrm{~mm}$ at the reference wind speed of $5 \mathrm{~m} / \mathrm{s}$ (Fig. 7(c) and (d)), whereas it is the other way around for the reference wind speed of $10 \mathrm{~m} / \mathrm{s}$ (Fig. 7(a) and (b)), except for a part in the middle of the building. Furthermore, the quotient of specific catch ratios is higher in the middle of the facade than at the side edge for both raindrop sizes, as well as for both reference wind speed values. This area coincides with the area with quasivertical trajectories in Fig. 6(a), which are relatively less parallel to the facade in Fig. 6(b), when turbulent dispersion is included. 
Fig. 8(a) and (b) show the turbulence intensity values upstream of the building in the vertical side and centerplanes. The turbulence intensity is calculated by $u^{\prime} / U$, where $u$ ' is the root mean square of the turbulent fluctuations and $U$ is the mean wind speed. $u$ ' can be computed as:

$$
u^{\prime}=\sqrt{\frac{2}{3} k}
$$

where $k$ denotes the turbulence kinetic energy. The turbulence intensity values indicate how large the turbulent velocity fluctuations are compared to the mean velocity. Larger turbulence intensity values in the centerplane agree with the larger increase in specific catch ratio profiles in the middle of the building (see Fig. 7(b) and (d)). Therefore, there is a clear connection between the turbulence kinetic energy values and the estimation of turbulent dispersion.

\subsection{Catch ratio charts}

The catch ratio charts can be obtained for specific positions on the facade using the calculated specific catch ratio values for various couples of reference wind speed and reference horizontal rainfall intensity. Fig. 9 shows the catch ratio charts for height values, $y=5$, 20,35 and $50 \mathrm{~m}$, at the side edge and in the middle. At the highest position on the facade at the side edge (Fig. 9(a)), turbulent dispersion has no effect except for low rainfall intensities and high reference wind speed values. For the remaining positions at the side edge (Fig. 9(c), (e) and (g)), the effect of turbulent dispersion is also visible for high rainfall intensities although it is still more prominent at low rainfall intensities and high wind speed values. For the values in the middle (Fig. 9(b), (d), (f) and (h)), the qualitative behavior is similar, however, the relative increase of catch ratio values due to turbulent dispersion is larger, as discussed in section 5.1.

In Fig. 9(a), the catch ratio values without turbulent dispersion increase as the rainfall intensity decreases, whereas this effect is not clear at lower positions at the side edge. In Fig. $9(\mathrm{~g})$, the values even decrease a little without turbulent dispersion modeling. On the other hand, in the middle, the curvature of the chart at low rainfall intensity values is not upward even at the highest position on the facade without turbulent dispersion. There exists a critical line on the facade above which the catch ratio values increase at lower rainfall intensities due to acceleration of the flow field above the roof. At positions lower than this line however, the smaller raindrops tend to move away from the facade due to the recirculation zone upstream of the building. Thus, the catch ratio values decrease at lower rainfall intensities. The effect of the recirculation zone is found to be higher in the middle of the building. The position of the critical line is influenced by several parameters, such as building geometry and reference wind speed. Additionally, the turbulent dispersion modeling moves the position of the critical line further down on the facade. This is due to the fact that the smaller droplets, which move away from the facade because of the recirculation zone, tend to hit the facade more frequently (See Fig. 6).

\section{Validation with experimental case}

\subsection{Geometry and measurement data}

In the work of Kubilay et al. [29], the EM model without turbulent dispersion was applied to the Hunting Lodge St. Hubertus in the Netherlands (a historical building with a monumental tower). The EM model was validated by comparing the catch ratio values with available experimental data [26] and with the values estimated by the LPT model. In that work, the deviations of the numerical values from the experimental data, especially at the lower parts of the tower, were attributed to the fact that the modeling did not take the turbulent dispersion into account. In this section, the catch ratio on the windward facade of the tower is estimated using the EM model with turbulent dispersion modeling.

Fig. 10 shows the computational grid of the building. The grid, the boundary conditions and the solver settings are kept the same as in the previous WDR studies on the same building $[26,29]$ for the sake of comparison. The inlet boundary conditions for the profiles for the mean wind speed and the dissipation rate of turbulence kinetic energy are similar to the ones described in section 4.2.1. The inlet profile of turbulence kinetic energy is defined by Eq. (27).

$k(y)=\left(I_{u} U(y)\right)^{2}$

The streamwise turbulence intensity, $I_{u}$, is taken to be $31 \%$ at a height of $2 \mathrm{~m}$ and $8 \%$ at the top of the domain in this study. The remaining boundary conditions are the same as the ones described in sections 4.2.1 and 4.2.2.

The measurements of reference wind speed, wind direction and horizontal rainfall intensity were performed at a meteorological station, located the north-west of the building [26]. The horizontal rainfall intensity was measured by a tipping bucket rain gauge with a horizontal orifice. The WDR measurements were conducted with WDR gauges that contain tipping bucket mechanisms. The WDR 
gauges have six times higher resolution than the standard rain gauges. Most of the WDR gauges were located on the south-west facade of the tower, as this facade showed severe moisture-related deterioration due to the prevailing south-west wind direction during rain events. Fig. 11(a) and (b) show the rain events on September 17th, 2007 and September 25th, 2007, respectively. The rain events with minimum measurement errors have been selected according to the guidelines by Blocken and Carmeliet [11]. More detailed information on the WDR measurements can be found in [26].

\subsection{Results}

Fig. 12 shows catch ratio distribution of the windward facade of the tower for the two rain events. Fig. 12(a) and (e) show the measured values [26], Fig. 12(b) and (f) show the estimated catch ratio distribution using the EM model without turbulent dispersion in Kubilay et al. [29], and Fig. 12(c) and (g) show the distribution with turbulent dispersion modeling for the rain events on September $17^{\text {th }}, 2007$ and September $25^{\text {th }}, 2007$, respectively. Note that although the estimated catch ratio values increase by including turbulent dispersion, the effect is not very pronounced. Actually, the turbulent dispersion is only found to be effective for the range of smallest raindrops, i.e. 0.3-0.5 mm. Even though the catch ratio values are closer to the measured values, they are still underestimating the WDR measurements. In section 5.1, it was shown that the calculated turbulence kinetic energy profile has a large influence on the response coefficient values and, as a result, on the amount of turbulent transport. In fact, the catch ratio distribution is very sensitive to the calculated turbulence kinetic energy field. Fig. 13 shows how the turbulence kinetic energy values decrease by up to a factor of 3 across the domain, despite the fact that the mean wind speed profile remains the same. The incident flow profiles are obtained in an empty domain at the position where the tower would be located. For an accurate study, the profiles should be horizontally homogeneous because the inlet profiles actually correspond to the measured data obtained at a location close to the building. Nevertheless, several researchers [54,59-63] report a similar trend on the horizontal inhomogeneity of the kinetic energy profile even though the mean wind speed profile remains constant. The horizontal homogeneity is linked to the relation between the inlet boundary conditions, the wall boundary conditions, the surface roughness modeling and the computational grid [54].

An additional study has been performed in order to verify the dependence of the catch ratio values on the estimated turbulence kinetic energy field. For this study, the turbulence kinetic energy boundary condition at the inlet is scaled, so that the calculated incident profile of turbulence kinetic energy is closer to the measured data. Fig 13(b) shows the incident turbulence kinetic energy profile after scaling. The new turbulence kinetic energy profile after scaling is more accurate especially at the higher parts of the domain. At lower parts, the values still underestimate the intended values at the bottom of the tower and overestimate at the top of the tower. Note that the incident wind speed profile is still the same after scaling (see Fig. 13(a)). Fig. 12(d) and (h) show the calculated catch ratio distribution with the turbulent dispersion modeling for the rain events on September $17^{\text {th }}, 2007$ and September $25^{\text {th }}, 2007$, respectively. Using the modified inlet boundary condition for the turbulence kinetic energy, the catch ratio values are closer to the measured data for both rain events. The average deviation between simulations and measurements decreases from $18.0 \%$ to $11.4 \%$ for the rain event on September $17^{\text {th }}, 2007$, and from $30.1 \%$ to $20.8 \%$ for the rain event on September $25^{\text {th }}, 2007$. The discrepancy decreases especially for the lower parts of the tower. The remaining discrepancy in the catch ratio values, even in the case with scaled inlet turbulence kinetic energy values, could be due to errors in the measurements, or related to modeling, such as geometrical simplifications and/or incorrect estimation of the recirculation regions. Note that the scaling of the inlet turbulence kinetic energy values is performed as a means to study the sensitivity of catch ratio values on the estimated turbulence kinetic energy. A better approach would be to ensure a higher consistency between the inlet conditions, the wall function roughness modifications, the turbulence model and the grid. This is an important research topic for further study.

\section{Discussion}

The integration of turbulent dispersion into the EM model allows quantification of the influence of wind velocity fluctuations on the WDR intensities. Its influence is especially high in regions where the wind-blocking effect is large and the wind velocity fluctuations are strong enough compared to the inertia of raindrops. By looking at the catch ratio charts in Fig. 9, the effect of turbulent dispersion seems to be present over the whole facade, especially at lower reference rainfall intensity values. There is a relation between the quotient $\eta^{\prime}{ }_{d} / \eta_{d}$ and the turbulence intensity values close to the facade (see Fig. 6 and 7). The sensitivity of the catch ratio values with turbulent dispersion on the estimated turbulence kinetic energy field is further verified with the case study on the Hunting Lodge St. Hubertus.

The study on the Hunting Lodge St. Hubertus verifies that the catch ratio values can be successfully estimated when turbulent dispersion is taken into account. The underestimation of the catch ratios at lower parts of the tower has been reduced considerably as long as the turbulence kinetic energy field is estimated accurately. Regarding the remaining discrepancy compared to the measurements, the simplified computational model itself could be influencing the results by neglecting some of the flow features. In effect, the geometrical details on the real building that may also have influenced the mean flow characteristics and/or led to local production of turbulence kinetic energy were not included. For example, the pitched roof at the lower parts of the building is actually modeled as a flat roof in the computational model. Additionally, the details on the building, such as the balcony on the upper part and 
the recessed facade are not included in the computational model. Briggen et al. [26] showed that the detailed model increased the catch ratio values up to $14 \%$ at the top part. Note that this is not related to turbulent dispersion but rather to the acceleration of the flow through the open part. The inclusion of the facade details also increases the turbulence kinetic energy values very close to the facade. However, the effect is found to be smaller compared to the increase due to turbulent dispersion. Further work is on-going to precisely determine the extent of geometry effects.

Further developments in the WDR prediction models are still possible. The turbulent dispersion modeling can increase the accuracy of WDR estimation for oblique wind flows and for geometries with more than one building, e.g. street canyons, urban neighborhoods. For such complex geometries, deficiencies in the RANS modeling become more significant. Certain deficiencies of RANS $k-\varepsilon$ modeling around the windward facade edges and in the wake of the buildings have been reported [49, 64-66], such as the size of the wake and the location of reattachment. Blocken et al. [15] compared the standard $k-\varepsilon$ model, the Renormalisation Group (RNG) $k-\varepsilon$ model, the realizable k- $\varepsilon$ model and the Reynolds stress model (RSM) with wind-tunnel measurements using three different building geometries. Even though RSM provided more accurate results compared to the other models, it still lacked the desired accuracy due to the previously mentioned deficiencies of RANS modeling. Thus, Detached Eddy Simulation (DES) or Large Eddy Simulation (LES) are suggested in order to achieve more accurate results in complex geometries. Similarly, Tominaga et al. [66] showed that reattachment length behind a single building is reproduced in a much better way by LES computations compared to various $k-\varepsilon$ models. LES calculations can provide a more accurate flow field, which may increase the accuracy of the mean flow WDR analysis with turbulent dispersion.

\section{Conclusion}

In this paper, a modeling approach is proposed to integrate turbulent dispersion into the mean WDR analysis. The model has been applied on two different buildings. The Reynolds stresses obtained in the rain phase momentum equation is modeled according to the eddy viscosity assumption and the turbulent viscosity of the rain phase is related to the turbulent viscosity of air phase by a coefficient. It has been shown that, with turbulent dispersion modeling, the catch ratio values increase throughout the windward facade of a high-rise building. The influence of the turbulent dispersion is more pronounced for low reference rainfall intensity and high reference wind speed values, and relatively more pronounced at lower parts of the facade. The increase in the catch ratio values with turbulent dispersion is linked with the turbulence kinetic energy profiles. This is verified with both the high-rise building and the case of Hunting Lodge St. Hubertus. It is shown that the average deviations between simulations and measurements have been decreased considerably by modifying the turbulence kinetic energy inlet boundary condition to counter the effect of flow development between the inlet plane and the building.

\section{Acknowledgements}

The research was supported through the Swiss National Science Foundation (SNF) - Project no. 135510.

\section{References}

[1] Blocken B, Carmeliet J. A review of wind-driven rain research in building science. J Wind Eng Ind Aerodyn. 2004;92:1079-1130. [2] Blocken B, Carmeliet J. Overview of three state-of-the-art wind-driven rain assessment models and comparison based on model theory. Build Environ. 2010;45:691-703.

[3] Erkal A, D'Ayala D, Sequeira L. Assessment of wind-driven rain impact, related surface erosion and surface strength reduction of historic building materials. Build Environ. 2012;57:336-348.

[4] Jorgensen GJ, Terwilliger KM, DelCueto JA, Glick SH, Kempe MD, Pankow JW, et al. Moisture transport, adhesion, and corrosion protection of PV module packaging materials. Solar Energy Materials and Solar Cells. 2006;90:2739-2775.

[5] Kempe MD. Modeling of rates of moisture ingress into photovoltaic modules. Solar Energy Materials and Solar Cells. 2006;90:27202738.

[6] Meyer EL, van Dyk EE. Assessing the reliability and degradation of photovoltaic module performance parameters. Reliability, IEEE Transactions on. 2004;53:83-92.

[7] Sanders $\mathrm{CH}$, Phillipson MC. UK adaptation strategy and technical measures: the impacts of climate change on buildings. Building

Research \& Information. 2003;31:210-221.

[8] Blocken B, Carmeliet J. Spatial and temporal distribution of driving rain on a low-rise building. Wind Struct. 2002;5:441-462.

[9] Blocken B, Derome D, Carmeliet J. Rainwater runoff from building facades: A review. Build Environ. 2013;60:339-361.

[10] Blocken B, Carmeliet J. High-resolution wind-driven rain measurements on a low-rise building - experimental data for model development and model validation. J Wind Eng Ind Aerodyn. 2005;93:905-928.

[11] Blocken B, Carmeliet J. On the accuracy of wind-driven rain measurements on buildings. Build Environ. 2006;41:1798-1810.

[12] Högberg A, Kragh M, van Mook FJR. A comparison of driving rain measurements with different gauges. 5th Symposium of Building Physics in the Nordic Countries, Göteborg, Sweden. 1999. p. 361-368.

[13] ISO 2009. Hygrothermal performance of buildings - calculation and presentation of climatic data - Part 3: calculation of a driving rain index for vertical surfaces from hourly wind and rain data. ISO 15927-3:2009 International Organization for Standardization. 
[14] Sanders C. Heat, air and moisture transfer in insulated envelope parts. IEA Annex 24, Final report - Vol 2, Task 2: Environmental conditions Acco Leuven, Leuven, Belgium1996.

[15] Blocken B, Dezso G, van Beeck J, Carmeliet J. The mutual influence of two buildings on their wind-driven rain exposure and comments on the obstruction factor. J Wind Eng Ind Aerodyn. 2009;97:180-196.

[16] Blocken B, Stathopoulos T, Carmeliet J, Hensen JLM. Application of computational fluid dynamics in building performance simulation for the outdoor environment: an overview. Journal of Building Performance Simulation. 2011;4:157-184.

[17] Moonen P, Defraeye TWJ, Dorer V, Blocken B, Carmeliet J. Urban physics : effect of the microclimate on comfort, health and energy demand. Frontiers of Architectural Research. 2012.

[18] Blocken B, Abuku M, Nore K, Briggen PM, Schellen HL, Thue JV, et al. Intercomparison of wind-driven rain deposition models based on two case studies with full-scale measurements. J Wind Eng Ind Aerodyn. 2011;99:448-459.

[19] Choi ECC. Numerical simulation of wind-driven rain falling onto a 2-D building. Asia Pacific Conf. on Computational Mechanics, Hong Kong. 1991. p. 1721-1728.

[20] Choi ECC. Simulation of wind-driven-rain around a building. J Wind Eng Ind Aerodyn. 1993;46-47:721-729.

[21] Choi ECC. Determination of wind-driven-rain intensity on building faces. J Wind Eng Ind Aerodyn. 1994;51:55-69.

[22] Choi ECC. Modelling of wind-driven rain and its soil detachment effect on hill slopes. J Wind Eng Ind Aerodyn. 2002;90:1081-

1097.

[23] Choi ECC. Numerical modelling of gust effect on wind-driven rain. J Wind Eng Ind Aerodyn. 1997;72:107-116.

[24] Blocken B, Carmeliet J. The influence of the wind-blocking effect by a building on its wind-driven rain exposure. J Wind Eng Ind Aerodyn. 2006;94:101-127.

[25] Blocken B, Carmeliet J. Validation of CFD simulations of'wind-driven rain on a low-rise building facade. Build Environ.

2007;42:2530-2548.

[26] Briggen PM, Blocken B, Schellen HL. Wind-driven rain on the facade of a monumental tower: numerical simulation, full-scale validation and sensitivity analysis. Build Environ. 2009;44:1675-1690.

[27] van Mook FJR. Driving rain on building envelopes. Ph.D. thesis, Eindhoven University of Technology, Eindhoven, The Netherlands; 2002.

[28] Huang SH, Li QS. Numerical simulations of wind-driven rain on building envelopes based on Eulerian multiphase model. J Wind Eng Ind Aerodyn. 2010;98:843-857.

[29] Kubilay A, Derome D, Blocken B, Carmeliet J. CFD simulation and validation of wind-driven rain on a building facade with an Eulerian multiphase model. Build Environ. 2013;61:69-81.

[30] Lakehal D, Mestayer PG, Edson JB, Anquetin S, Sini JF. Eulero-Lagrangian simulation of raindrop trajectories and impacts within the urban canopy. Atmospheric Environment. 1995;29:3501-3517.

[31] Hangan H. Wind-driven rain studies. A C-FD-E approach. J Wind Eng Ind Aerodyn. 1999;81:323-331.

[32] Etyemezian V, Davidson Cl, Zufall M, Dai W, Finger S, Striegel M. Impingement of rain drops on a tall building. Atmospheric

Environment. 2000;34:2399-2412.

[33] Huang S, Li Q. Large eddy simulation of wind-driven rain on tall building facades. Journal of Structural Engineering. 2012;138:967983.

[34] Shih T-H, Liou WW, Shabbir A, Yang Z, Zhu J. A new k- $\epsilon$ eddy viscosity model for high reynolds number turbulent flows.

Computers \& Fluids. 1995;24:227-238.

[35] Hill DP. The computer simulation of dispersed two-phase flow. Ph.D. thesis, Imperial College of Science, Technology \& Medicine, Department of Mechanical Engineering, London, UK.; 1998.

[36] Rusche H. Computational fluid dynamics of dispersed two-phase flows at high phase fractions. Ph.D. thesis, Imperial College of

Science, Technology \& Medicine, Department of Mechanical Engineering, London, UK.; 2002.

[37] de Wolf DA. On the Laws-Parsons distribution of raindrop sizes. Radio Science. 2001;36:639-642.

[38] Gosman AD, Lekakou C, Politis S, Issa RI, Looney MK. Multidimensional modeling of turbulent two-phase flows in stirred vessels.

AIChE Journal. 1992;38:1946-1956.

[39] Gousseau P, Blocken B, van Heijst GJF. CFD simulation of pollutant dispersion around isolated buildings: On the role of convective and turbulent mass fluxes in the prediction accuracy. J Hazard Mater. 2011;194:422-434.

[40] Loth E. Numerical approaches for motion of dispersed particles, droplets and bubbles. Progress in Energy and Combustion

Science. 2000;26:161-223.

[41] Boussinesq J. Essai sur la théorie des eaux courantes. Mémoires présentés par divers savants à l'Académie des Sciences. 1887;23:1-680.

[42] Issa RI, Oliveira PJ. Modelling of turbulent dispersion in two phase flow jets. Engineering turbulence modeling and experiments 21993. p. 947-957.

[43] Shirolkar JS, Coimbra CFM, McQuay MQ. Fundamental aspects of modeling turbulent particle dispersion in dilute flows. Progress in Energy and Combustion Science. 1996;22:363-399.

[44] Politis S. Prediction of two-phase solid-liquid turbulent flow in stirred vessels. PhD thesis, Imperial College of Science, Technology and Medicine, University of London; 1989.

[45] Chen CP, Wood PE. A turbulence closure model for dilute gas-particle flows. The Canadian Journal of Chemical Engineering.

1985;63:349-360.

[46] Issa RI. A simple model for Ct. Private Communication. December 1992.

[47] Melville WK, Bray KNC. A model of the two-phase turbulent jet. Int J Heat Mass Transfer. 1979;22:647-656.

[48] Best AC. The size distribution of raindrops. Quarterly Journal of the Royal Meteorological Society. 1950;76:16-36.

[49] Tominaga Y, Mochida A, Yoshie R, Kataoka H, Nozu T, Yoshikawa M, et al. AlJ guidelines for practical applications of CFD to pedestrian wind environment around buildings. J Wind Eng Ind Aerodyn. 2008;96:1749-1761. 
[50] Franke J, Hellsten A, Schlunzen KH, Carissimo B. The COST 732 Best practice guideline for CFD simulation of flows in the urban environment: a summary. International Journal of Environment and Pollution. 2011;44:419-427.

[51] Wieringa J. Updating the Davenport roughness classification. J Wind Eng Ind Aerodyn. 1992;41:357-368.

[52] Launder BE, Spalding DB. The numerical computation of turbulent flows. Comput Methods Appl Mech Eng. 1974:269-289.

[53] Cebeci T, Bradshaw P. Momentum transfer in boundary layers. New York: Hemisphere Publishing Corporation; 1977.

[54] Blocken B, Stathopoulos T, Carmeliet J. CFD simulation of the atmospheric boundary layer: wall function problems. Atmospheric Environment. 2007; 41:238-252.

[55] OpenCFD Ltd. OpenFOAM v2.0.1 Documentation. 2011.

[56] Gunn R, Kinzer GD. The terminal velocity of fall for water droplets in stagnant air. Journal of Meteorology. 1949;6:243-248.

[57] Pope SB. Turbulent flows: Cambridge University Press; 2000.

[58] Defraeye TWJ. Convective heat and mass transfer at exterior building surfaces. Ph.D. thesis, Katholieke Universiteit Leuven, Leuven, Belgium.; 2011.

[59] Hargreaves DM, Wright NG. On the use of the k-epsilon model in commercial CFD software to model the neutral atmospheric boundary layer. J Wind Eng Ind Aerodyn. 2007;95:355-369.

[60] O'Sullivan JP, Archer RA, Flay RGJ. Consistent boundary conditions for flows within the atmospheric boundary layer. J Wind Eng Ind Aerodyn. 2011;99:65-77.

[61] Parente A, Gorle C, van Beeck J, Benocci C. Improved kappa-epsilon model and wall function formulation for the RANS simulation of ABL flows. J Wind Eng Ind Aerodyn. 2011;99:267-278.

[62] Richards PJ, Hoxey RP. Appropriate boundary conditions for computational wind engineering models using the k- $\epsilon$ turbulence model. J Wind Eng Ind Aerodyn. 1993;46-47:145-153.

[63] Blocken B, Carmeliet J, Stathopoulos T. CFD evaluation of wind speed conditions in passages between parallel buildings - effect of wall-function roughness modifications for the atmospheric boundary layer flow. J Wind Eng Ind Aerodyn. 2007;95:941-962.

[64] Murakami S. Computational wind engineering. J Wind Eng Ind Aerodyn. 1990;36:517-538.

[65] Murakami S. Comparison of various turbulence models applied to a bluff-body. J Wind Eng Ind Aerodyn. 1993;46-7:21-36.

[66] Tominaga Y, Mochida A, Murakami S, Sawaki S. Comparison of various revised k- $\varepsilon$ models and LES applied to flow around a high-rise building model with 1:1:2 shape placed within the surface boundary layer. J Wind Eng Ind Aerodyn. 2008;96:389-411. 


\section{Figures}

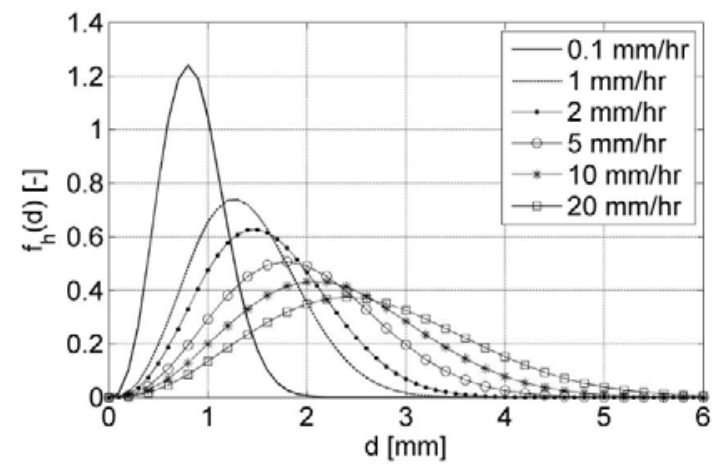

Fig. 1. Raindrop size distribution through a horizontal plane with the rainfall intensity as a parameter - calculated from raindrop size distribution in the air according to Best [46].

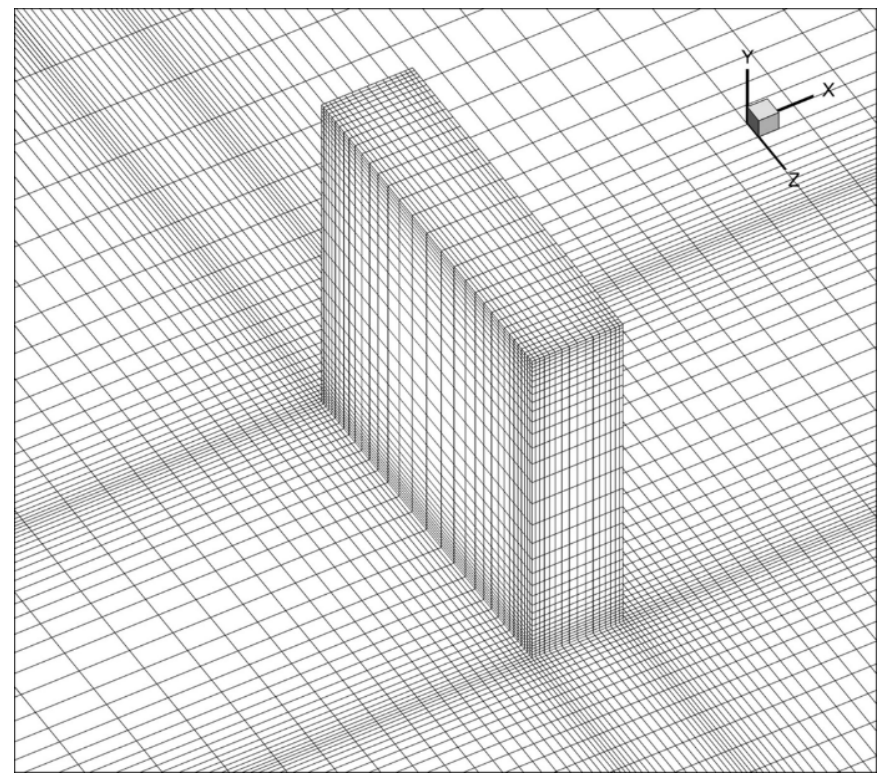

Fig. 2. Computational grid on building and part of the ground surface $(592,832$ cells).
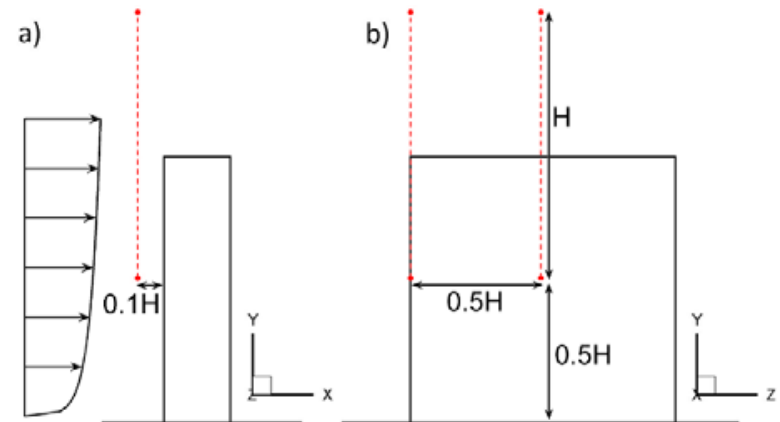

Fig. 3. Position of vertical lines for grid sensitivity analysis. 


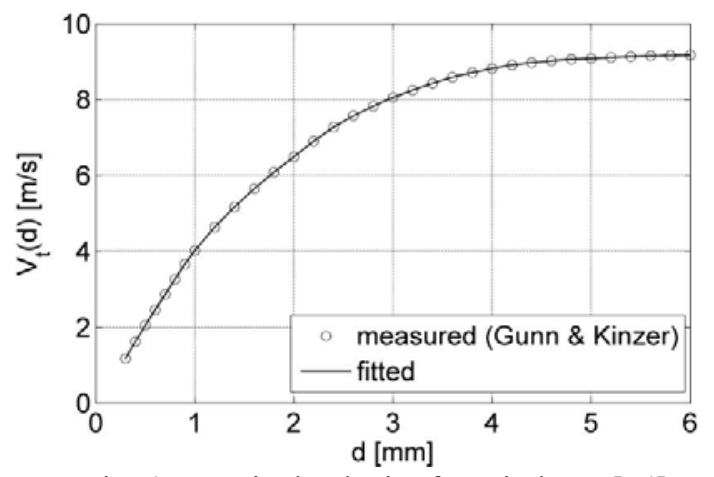

Fig. 4. Terminal velocity for raindrops [54].

a)

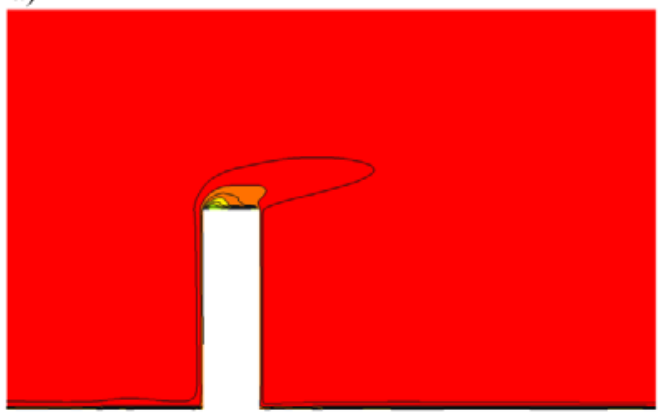

c)

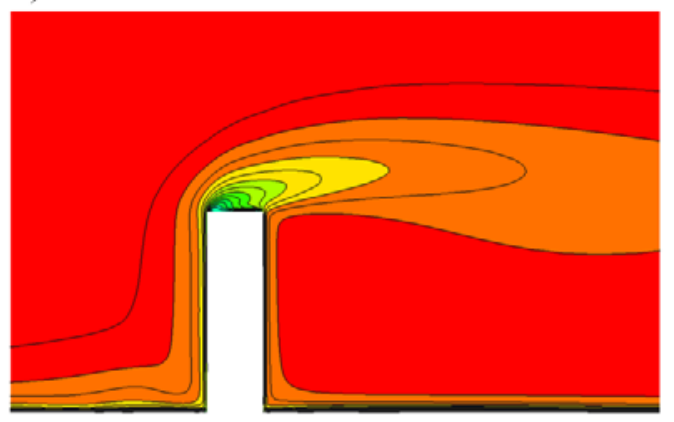

b)

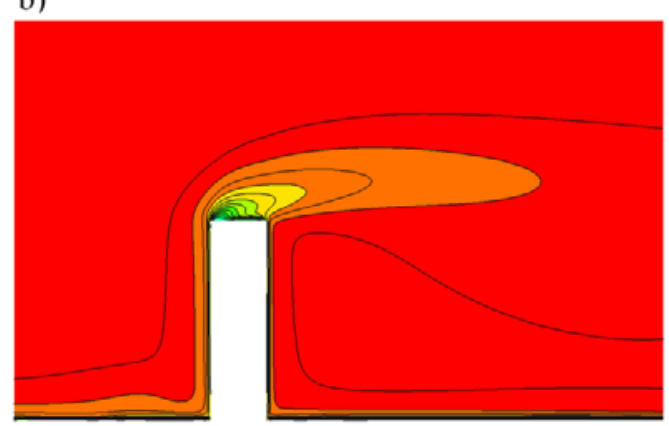

d)

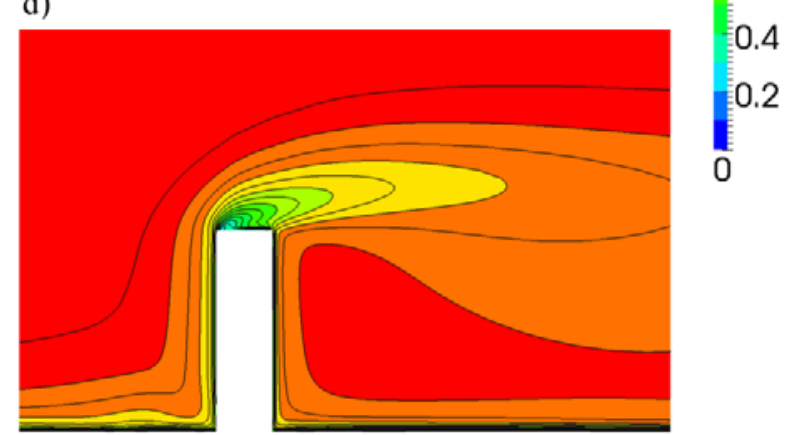

Fig. 5. Contours of response coefficient $C_{t}$ in the vertical centerplane for $U_{10}=10 \mathrm{~m} / \mathrm{s}$ for raindrop sizes of a) $0.3 \mathrm{~mm}$, b) $1.0 \mathrm{~mm}$, c) $2.0 \mathrm{~mm}$, and d) $5.0 \mathrm{~mm}$. 

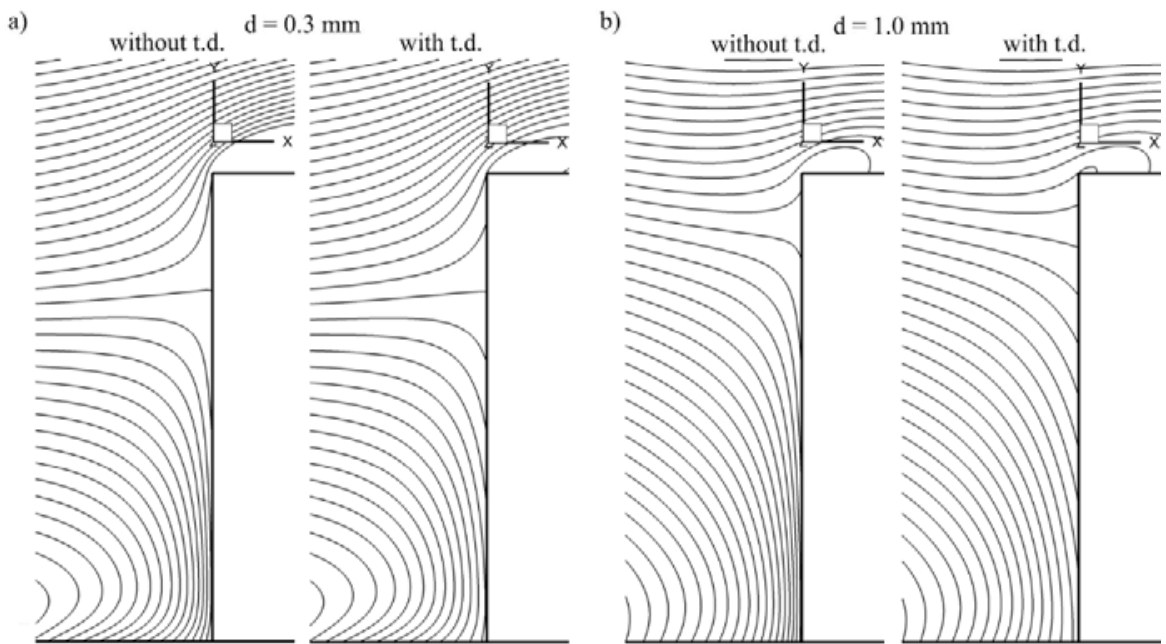

c)

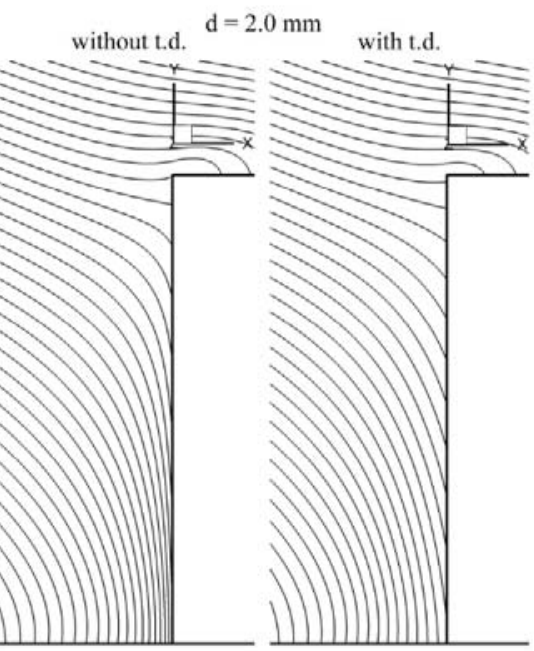

d)

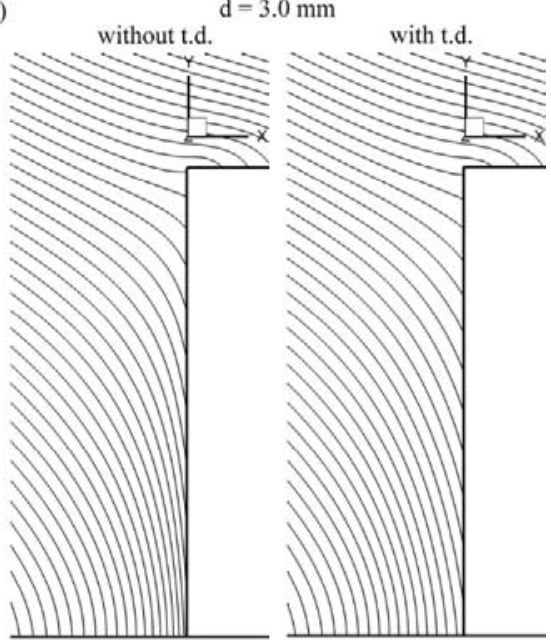

Fig. 6. Streamlines of the rain phase in the vertical centerplane for $U_{10}=10 \mathrm{~m} / \mathrm{s}$ and raindrop size of a) $\left.\left.0.3 \mathrm{~mm}, \mathrm{~b}\right) 1.0 \mathrm{~mm}, \mathrm{c}\right) 2.0$ $\mathrm{mm}, \mathrm{d}) 3.0 \mathrm{~mm}$ without and with turbulent dispersion. 
a)
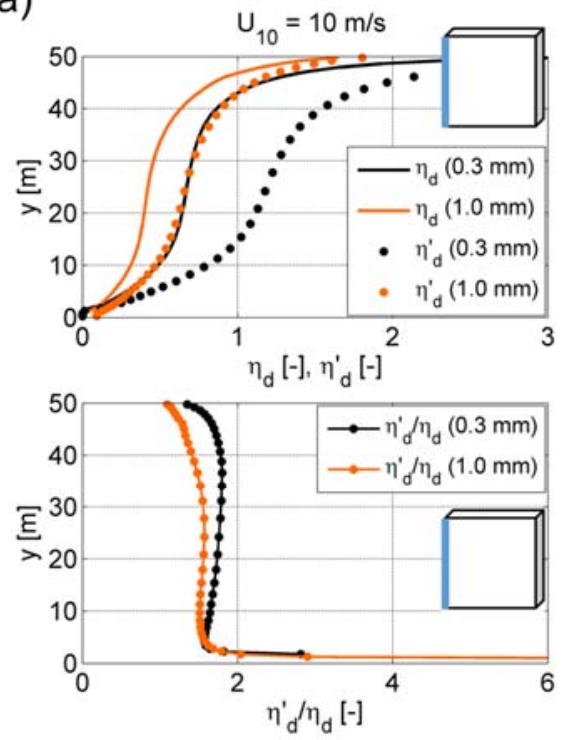

c)
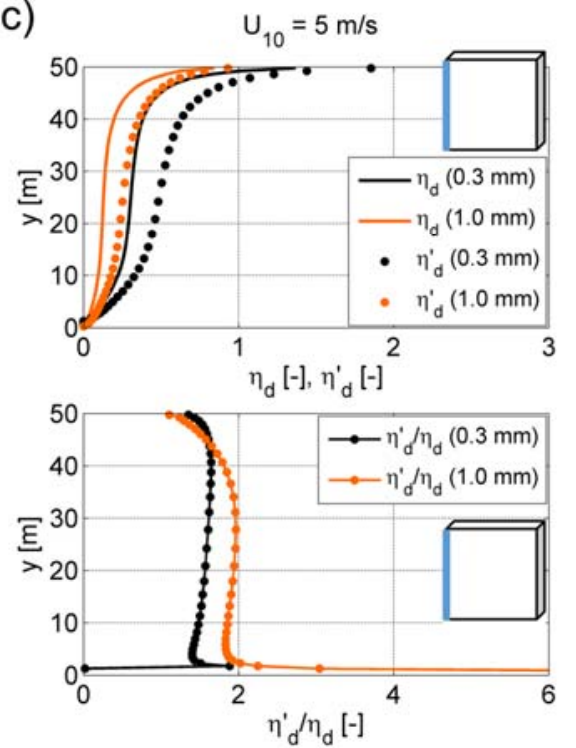

b)
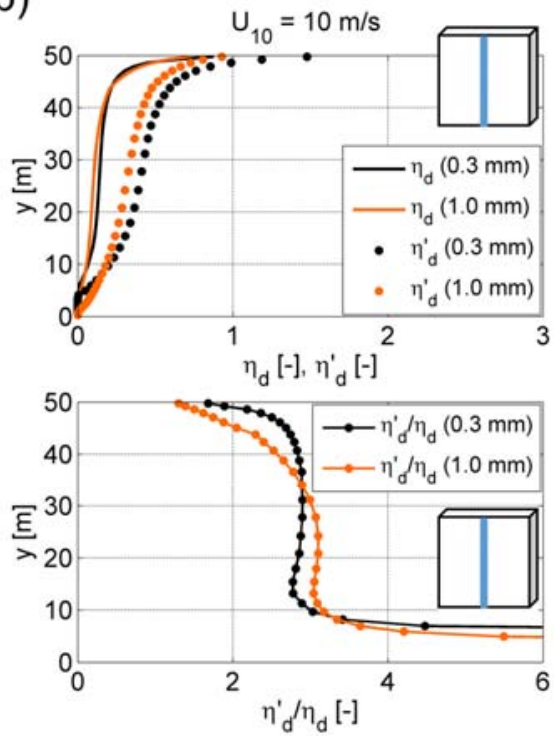

d)
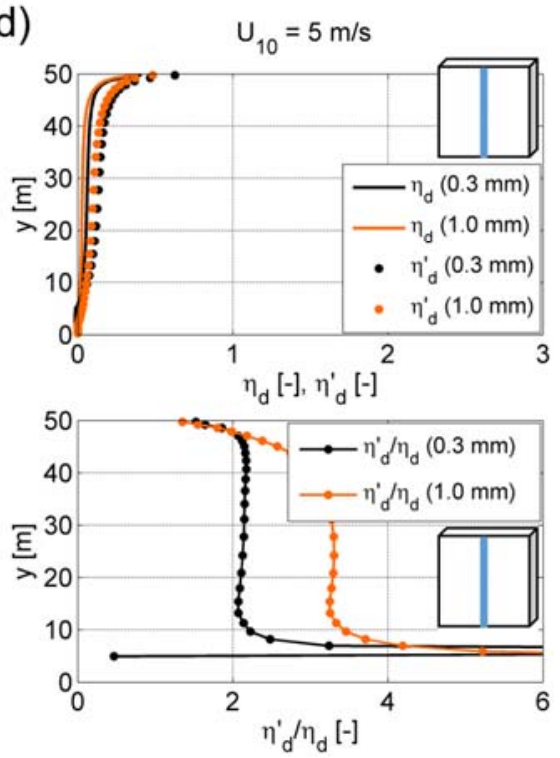

Fig. 7. Specific catch ratio and ratio of specific catch ratios (with and without turbulent dispersion) along a vertical line on the facade a) at the side edge, for $U_{10}=10 \mathrm{~m} / \mathrm{s}, \mathrm{b}$ ) in the middle, for $U_{10}=10 \mathrm{~m} / \mathrm{s}$, c) at the side edge, for $U_{10}=5 \mathrm{~m} / \mathrm{s}$ and d) in the middle for $U_{10}$ $=5 \mathrm{~m} / \mathrm{s}$. 
a)

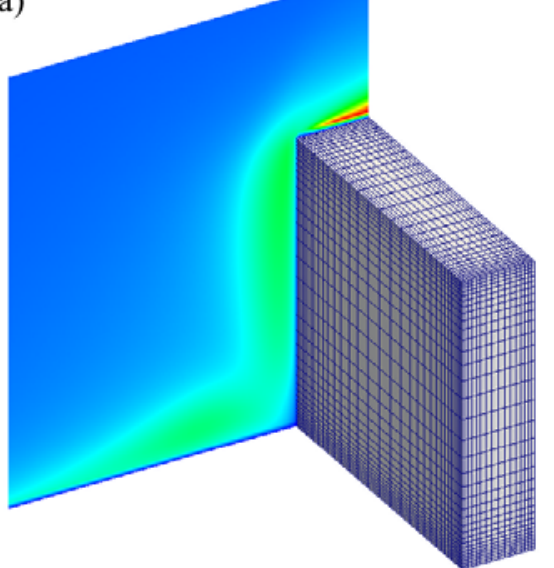

$\begin{array}{lllll}0 & 0.2 & 0.4 & 0.6 & 0.8 \\ 0\end{array}$ b)

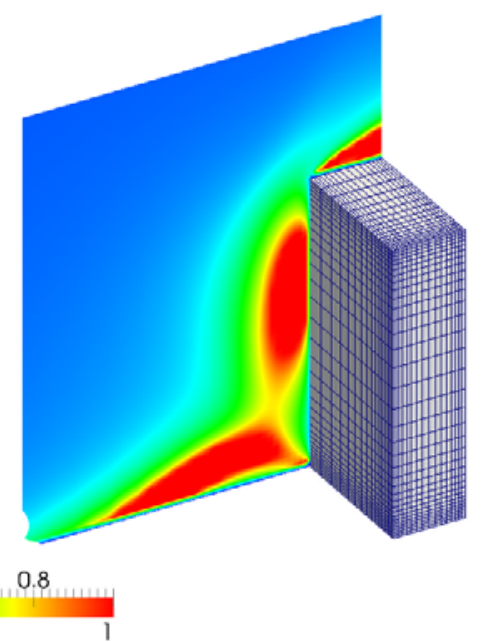

Fig. 8. Contours of turbulence intensity upstream of the building in (a) the vertical sideplane and (b) the vertical centerplane. 
a)

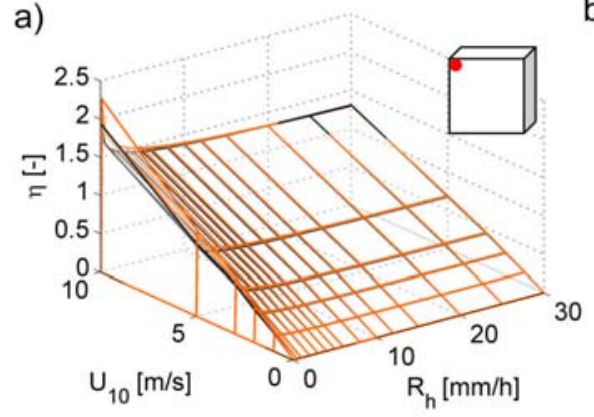

c)

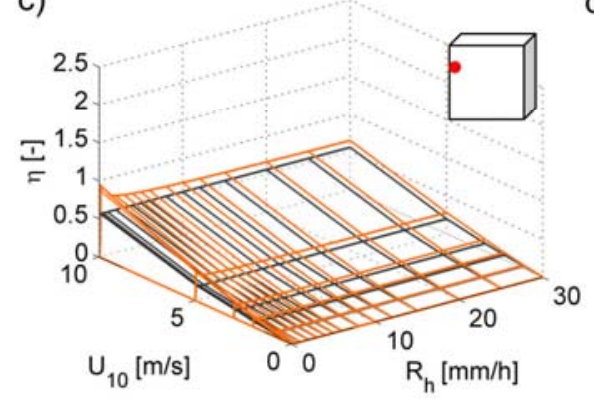

e)

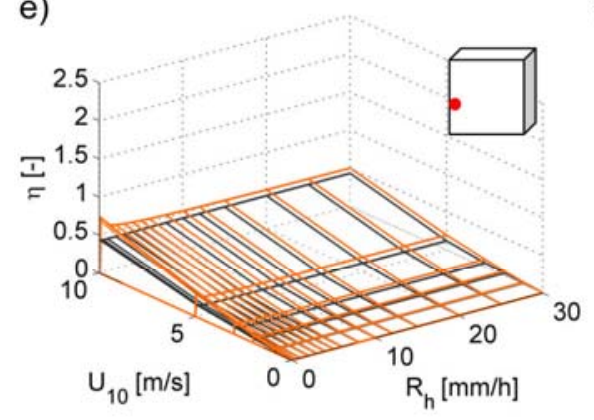

g)

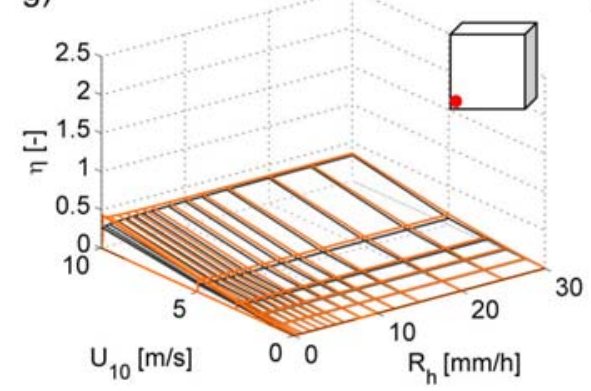

b)

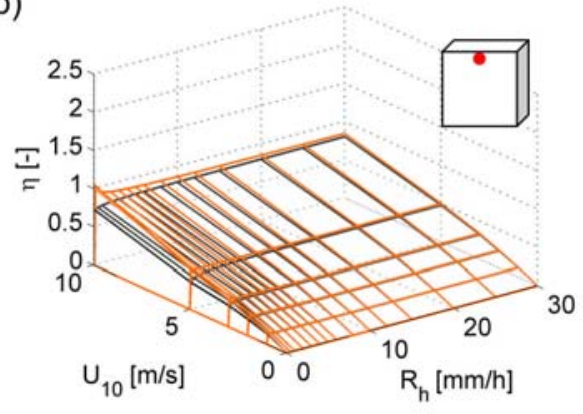

d)

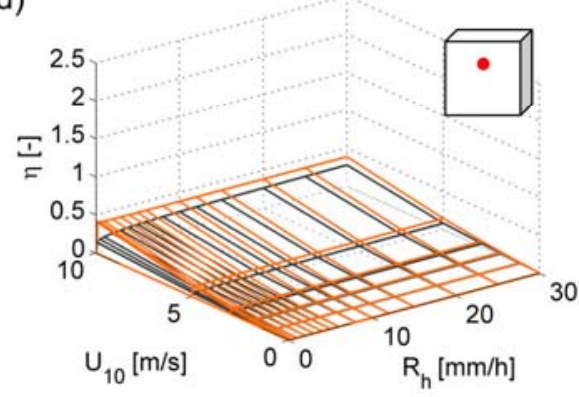

f)

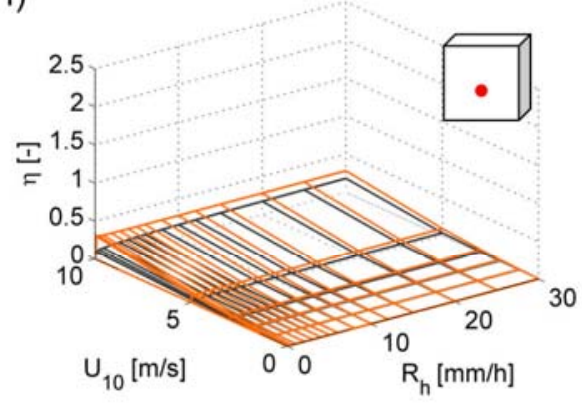

h)

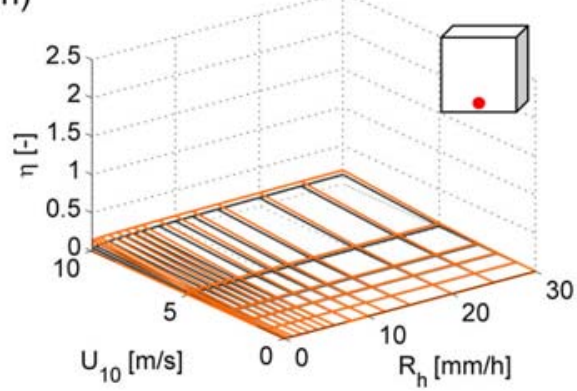

Fig. 9. Catch ratio charts on the windward facade for points at heights a-b) $y=50 \mathrm{~m}, \mathrm{c}-\mathrm{d}$ ) $\mathrm{y}=35 \mathrm{~m}, \mathrm{e}-\mathrm{f}) \mathrm{y}=20 \mathrm{~m}$, and g-h) $\mathrm{y}=5 \mathrm{~m}$, along a vertical line, left: at the side edge, right: in the middle (- : without turbulent dispersion, - : with turbulent dispersion). 


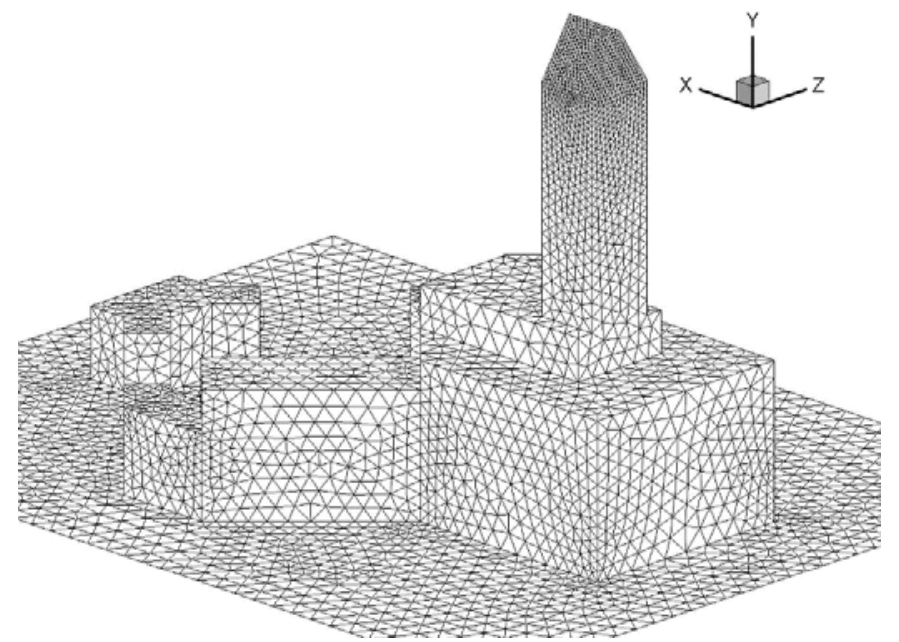

Fig. 10. Computational grid on building and part of the ground surface for Hunting Lodge St. Hubertus [26] (650,000 cells).
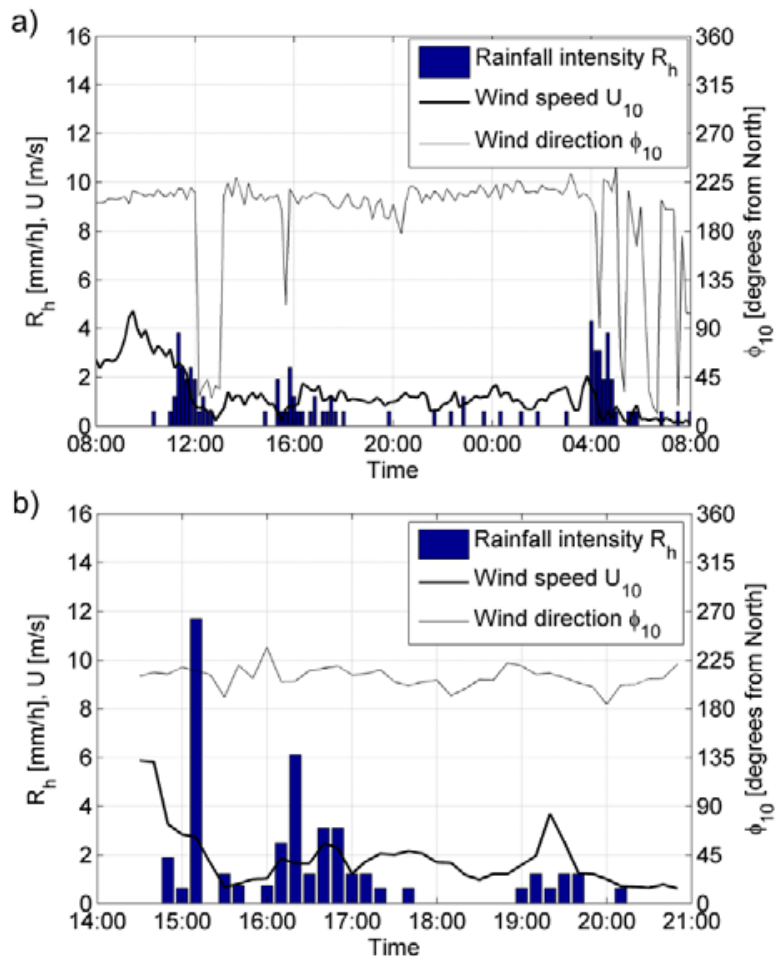

Fig. 11. Record of the meteorological data for the rain event on: a) September 17th, 2007, b) September 25th, 2007 [26]. 
a)

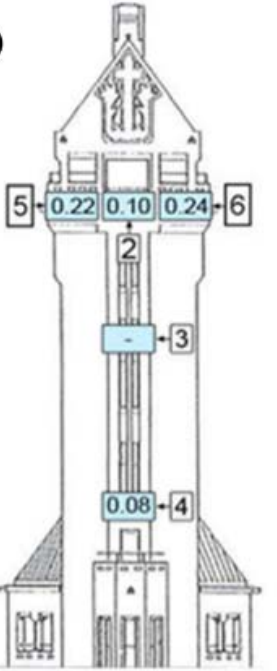

Measurements, September 17th

e)

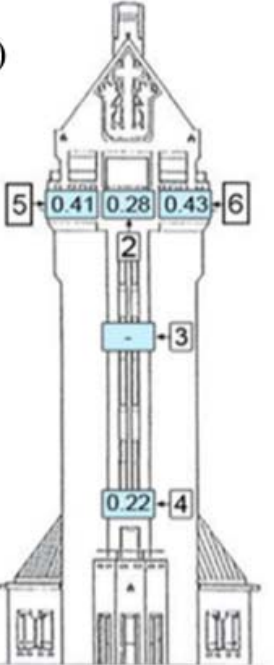

Measurements, September 25th b)

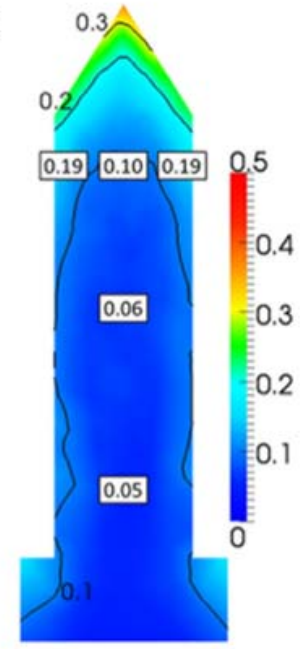

EM, September 17th c)

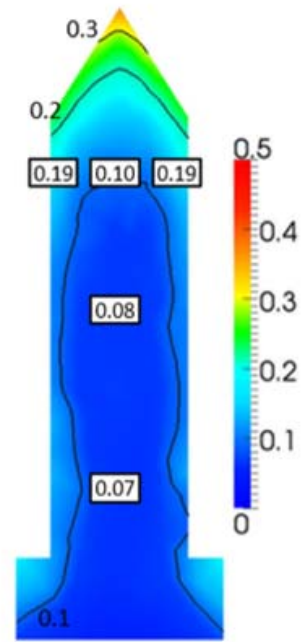

EM, September 17th Turbulent dispersion

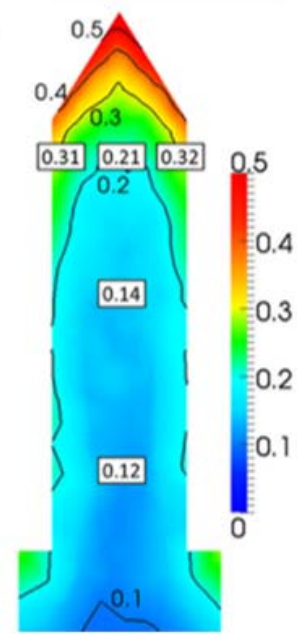

EM, September 25th g)

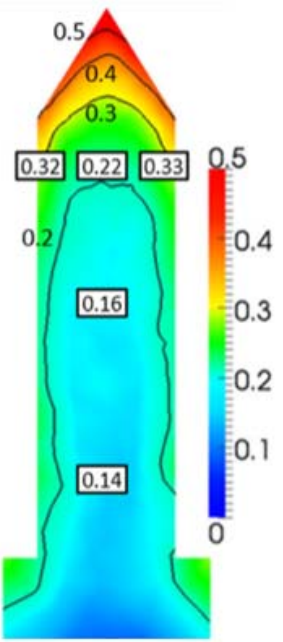

EM, September 25th

Turbulent dispersion d)

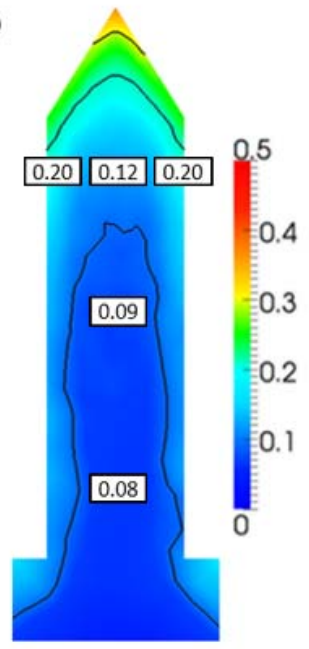

EM, September 17th Turbulent dispersion, Modified k

Fig. 12. Catch ratio distribution from measurement data [26] and numerical data [30] without and with turbulent dispersion model on the front facade of the tower after the rain events on: a-d) September 17th, 2007, e-h) September 25th, 2007. 

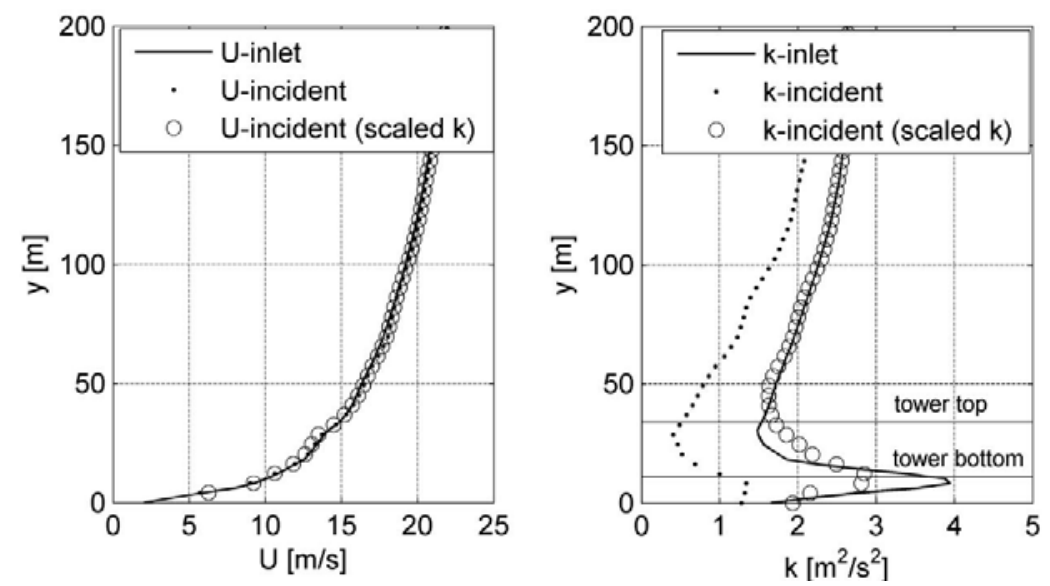

Fig. 13. Inlet and incident profiles of a) the mean wind speed and b) the turbulence kinetic energy.

\section{Glossary}

\begin{tabular}{|l|l|}
\hline$C_{d}$ & Drag coefficient \\
$C_{s}$ & Roughness constant \\
$C_{t}$ & Response coefficient \\
$C_{1}, C_{2}$ & Model parameters in the realizable $k-\varepsilon$ turbulence model \\
$d$ & Raindrop diameter \\
$f_{h}(d)$ & Probability density function of raindrop size falling through a horizontal plane \\
$g$ & Gravitational acceleration \\
$I_{u}$ & Streamwise turbulence intensity \\
$k$ & Turbulence kinetic energy \\
$k_{s}$ & Physical roughness height \\
$H$ & Height of the building \\
$\vec{n}$ & Normal vector \\
$p$ & Pressure \\
$P_{k}$ & Generation of turbulence kinetic energy due to mean velocity gradients \\
$R e$ & Reynolds number \\
$R e_{R}$ & Relative Reynolds number \\
$R_{h}$ & Horizontal rainfall intensity \\
$R_{w d r}$ & Wind-driven rain intensity \\
$S_{h}$ & Horizontal rainfall amount \\
$t_{p}$ & Particle relaxation time \\
$t_{f l}$ & Lagrangian fluid time scale \\
$u^{*}{ }_{A B L}$ & Friction velocity \\
$U_{10}$ & Reference wind speed at 10 m height in the upstream undisturbed flow \\
$U$ & Mean wind speed \\
$u_{i}^{\prime}$ & Fluctuating air phase velocity \\
$u_{k i}^{\prime}$ & Fluctuating rain phase velocity \\
$\left|V_{n}(k)\right|$ & Velocity magnitude of $k^{\text {th }}$ rain phase in the direction normal to the building facade \\
$V_{t}$ & Raindrop terminal velocity \\
$y$ & Height coordinate \\
$y_{0}$ & Aerodynamic roughness length \\
$y^{+}$ & Dimensionless wall distance \\
$\alpha_{k}$ & Volume fraction of $k^{\text {th }}$ rain phase \\
$\varepsilon$ & Turbulence dissipation rate \\
$\eta_{d}$ & Specific catch ratio \\
$\eta^{\prime}{ }_{d}$ & Specific catch ratio with turbulent dispersion modeling \\
$\eta$ & Catch ratio \\
\hline
\end{tabular}




\begin{tabular}{|l|l|}
\hline$\mu_{a}$ & Dynamic viscosity of air \\
$v_{a}$ & Kinematic viscosity of air \\
$v_{t, a}$ & Kinematic turbulent viscosity of air \\
$v_{t, d}$ & Kinematic turbulent viscosity of water \\
$\kappa$ & von Karman constant \\
$\rho_{a}$ & Density of air \\
$\rho_{w}$ & Density of water \\
$\sigma_{\varepsilon}$ & Turbulent Prandtl number for $\varepsilon$ \\
$\sigma_{k}$ & Turbulent Prandtl number for $k$ \\
$X_{k}$ & Phase indicator function \\
ABL & Atmospheric Boundary Layer \\
CFD & Computational Fluid Dynamics \\
DES & Detached Eddy Simulation \\
BE-HAM & Building Envelope - Heat, Air, Moisture transport \\
EM & Eulerian Multiphase Model \\
LES & Large Eddy Simulation \\
LPT & Lagrangian Particle Tracking \\
RANS & Reynolds-Averaged Navier-Stokes \\
WDR & Wind-Driven Rain \\
\hline
\end{tabular}

